\title{
Numerical Analysis of Steel Tubular Member Response to Ship Bow Impacts
}

\author{
Joao Travanca*, Hong Hao* \\ *School of Civil and Resource Engineering, the University of Western Australia \\ 35 Stirling Highway, Crawley, WA6009, Australia
}

\begin{abstract}
Offshore platforms and ship traffic can be close in proximity in some areas. This has become more likely as the maritime traffic as well as the number of offshore platforms has increased over the past decades. Although incidents involving collisions between these two structures have a low chance of occurrence, the effects of a ship impact, when occurs, can result in hazardous scenarios regarding the integrity of the platform. Current risk analysis of jacket installations is very limited when it comes to jacket legs being head-on impacted by vessels. As a result bow forces are usually estimated by assuming rigid offshore structures although it is commonly agreed that this simplification may not lead to accurate predictions of the contact force between ship and platform as the structural deformation of the platform also absorbs a significant amount of impact energy. On the other hand, deformations in the platform members are commonly predicted under the assumption that the ship hulls are strong enough to be treated as rigid. The present paper describes a detailed finite element model developed for impact analysis of merchant vessel bows against tubular members, representative of offshore jacket legs. The model comprises a general supply vessel in the range of 2000ton to 5000ton displacement and a vertical steel pipe representative of a jacket leg. Nonlinear inelastic responses of both the ship and tubular structures are considered. The numerical results are checked against tests by other authors to verify the accuracy of the model. The verified model is used to perform parametric simulations. Different geometrical parameters such as member length, wall thickness and diameter of the tubular members, as well as the boundary conditions, axial preloading and dynamic aspects such as the impact velocity and the strain rate effects are considered in the analyses to examine the performance of the platform under vessel impact. Based on intensive numerical results, discussions are made with respect to the accuracy of the current code of practice in offshore platform design to resist possible vessel impact.
\end{abstract}

\section{Introduction}

Offshore platforms are in most of the cases constituted by tubular steel members. In this paper, the response of tubular members to ship bow impacts is analyzed by means of FEM calculations. The study focuses on the analyses and predictions of damage pattern and damage intensity that can be provoked on jacket legs by ship impact as the collapse of such members would affect the integrity of the platform.

The effects of a ship impact can result in several scenarios regarding the integrity of the platform. These can range from moderate to catastrophic, depending on the ship involved, its velocity, as well as the stiffness and strength of the platform and the location of impact. For an accurate prediction of the performance of a platform under ship impact, the relative strength of both ship and platform structures should be accounted when analyzing how the kinetic energy of the system is converted into strain energy. 
The classical way the collision problem has been being approached is through quasi-static analyses, where the collision effects are assessed by following the laws of conservation of momentum and conservation of energy. The problem is then separated into external dynamics, involving the ship motion and hydrodynamic forces, and internal dynamics, involving the material deformations of the colliding structures. In most previous studies, to simplify the problem, many researchers consider only one impact structure is deformable and assume the other one is rigid. As a result, the impact loads are related to only the damage of the 'deformable' structure. However, it is commonly agreed that neglecting the deformation and damage of the other structure, either the ship or the platform, which may absorb significant amount of impact energy and hence affects the ship-platform structure interaction, may lead to inaccurate predictions of impact loads and structural responses.

Since head-on collisions from a ship can represent the most harmful cases for the integrity of the steel platform, it is of interest to assess with a certain level of detail how platforms are locally affected, and more precisely the hit tubular members by ship bows by considering deformation and damage of both ship bow and platform structure. The results will be used to check the accuracy and scope of the current design practice developed based primarily on the assumption that either ship or platform structure is rigid, and lead to better understanding of ship-platform structure interactions upon ship impacts.

\section{Background}

Often the effects of ship collisions on offshore platform structures are determined by impact energy together with simplified methods of structural analysis. The Norwegian Standard classifies the design principles according to the amount of strain energy dissipated through each of the structures, where the dissipated energy is a function of the relative strength between installation and ship.

\subsection{Bow deformation forces}

The quantification of the force that can be exerted by a ship bow with an initial velocity on a platform structure is usually made by assuming the ship crushing on a rigid wall that could be representative of relatively stiff bridge piers, large diameter columns or other ships or floating platforms insusceptible of any large deformation and yield. Minorsky (1959) estimated the relationship between the deformed steel volume and the absorbed impact energy based on investigation of various ship-ship collisions. Ship types can vary in size, shape and structure. Curves derived from numerical study performed by Pedersen et al. (1992) on ship impacts on rigid bridge pier or offshore platform estimate, for ships varying between 500 DWT coasters and 150000 DWT bulk vessels, that crushing loads can reach $700 \mathrm{MN}$ with initial speeds of up to $9.3 \mathrm{~m} / \mathrm{s}$. Defining a model to be representative for all the ship types and that could come across a jacket platform is not possible. Therefore, sorting ships with a certain degree of structural similarity into the same category would reduce the number of different models needed in numerical works.

Among the authors who have developed methods to analyze bow impacts, the method of Amdahl (1983) is discussed in detail here. Amdahl correlated model test results with theoretical considerations. The energy which is dissipated during the plastic deformation of structural elements such as angles, T-sections and cruciforms is considered (see Figure 1). 


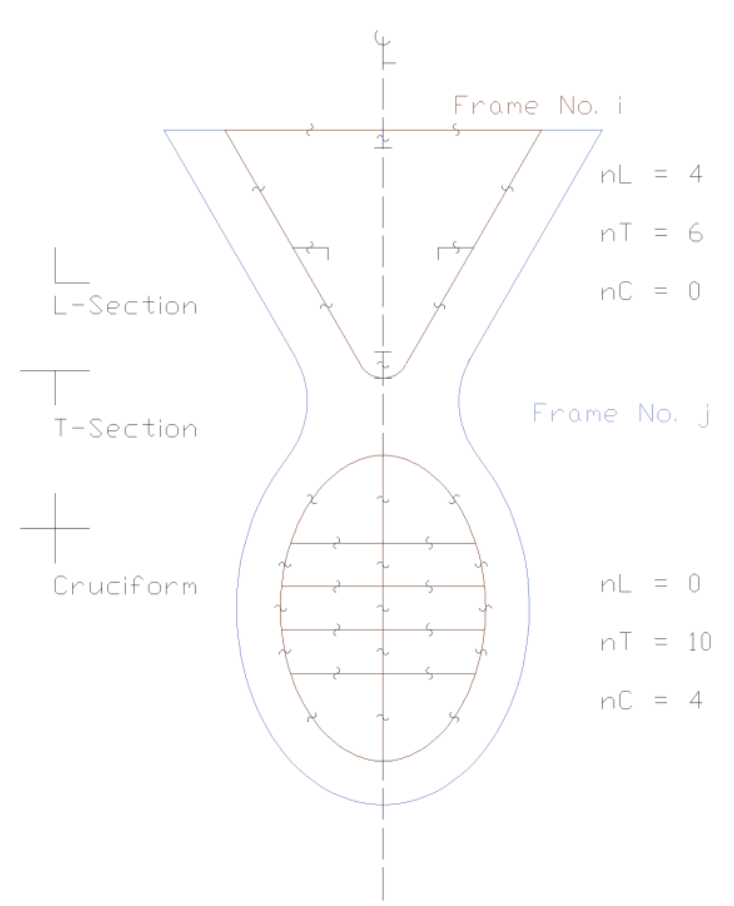

Figure 1. Method of cross-sections (Amdahl, 1983) to determine the number of intersections

The average crushing strength according to Amdahl's procedure is given by:

$$
\sigma_{c}=2.42 \sigma_{0}\left[n_{A T} t^{2} / A\right]^{0.67}\left[0.87+1.27 \frac{n_{c}+0.31 n_{T}}{n_{A T}}\left(\frac{A}{\left(n_{c}+0.31 n_{T}\right) t^{2}}\right)^{0.25}\right]^{0.67}
$$

and the total crushing load is obtained by multiplying $\sigma_{c}$ by the associated cross-sectional area of the deformed steel material, A. Here

$\sigma_{c} \quad$ average crushing strength of bow;

$\sigma_{0} \quad$ ultimate strength of steel (including strain rate effects); $t$ average thickness of the crosssection under consideration;

A cross-sectional area of the deformed steel material;

$\mathrm{n}_{\mathrm{c}} \quad$ number of cruciforms in the cross-section;

$\mathrm{n}_{\mathrm{T}} \quad$ number of $\mathrm{T}$-sections in the cross-section;

$\mathrm{n}_{\mathrm{AT}} \quad$ number of angle and T-sections in the cross section.

The magnitude of the dynamic flow stress $\sigma_{u}$ (Marsh and Campbell, 1963) is calculated as follows:

$$
\sigma_{u}(\dot{\varepsilon})=1.29 \sigma_{u s} \dot{\varepsilon}^{0.037}
$$

where $\sigma_{u s}$ is the static ultimate stress of the steel material; and the strain rate is taken as:

$$
\dot{\varepsilon}=v_{x} / S_{f}
$$

where

$v_{x} \quad$ velocity in longitudinal direction during impact;

$S_{f} \quad$ frame spacing.

This model proposed by Amdahl makes use of Wierzbicki's (1983) folding mechanisms. Yang and Caldwell (1988) assumed a similar way of energy dissipation during deformation of the structure. It 
differs from Amdahl's that the longitudinal stiffeners may be included through an equivalent thickness of the shell plating, equalizing the plastic bending moment of the equivalent plating and the plastic bending moment of the shell plating with longitudinal stiffeners. Furthermore, while Amdahl determines the folding length and crushing load by minimizing the deformation energy absorbed during the folding process, Yang and Caldwell take the folding length $\mathrm{H}$ the same as the space between the transverse frames, provided that the frame spacing is less than the theoretical folding length.

The numerical predictions by Amdahl and Yang and Caldwell are compared by Pedersen (1992), who derives his expression based on six different ships ranging from a small coaster to a large bulk carrier. To estimate the maximum bow collision load, Pedersen considers the influences of the bow vessel size, loading condition, and speed and strain rate effects. The expression becomes:

$$
P_{\text {bow }}=\left\{\begin{array}{c}
P_{0} \cdot \bar{L}\left[\bar{E}_{i m p}+(5-\bar{L}) \cdot \bar{L}^{1.6}\right]^{0.5}, \bar{E}_{i m p} \geq \bar{L}^{2.6} \\
2.24 . P_{0}\left[\bar{E}_{i m p} \cdot \bar{L}\right]^{0.5}, \bar{E}_{i m p}<\bar{L}^{2.6}
\end{array}\right.
$$

where

$\bar{L}=L / 275 \mathrm{~m}$

$\bar{E}_{i m p}=E_{i m p} / 1425 \mathrm{MNm}$

$E_{\text {imp }}=\frac{1}{2} m_{x} V_{0}^{2}$

$P_{\text {bow }}$ maximum bow collision load [MN];

$P_{0} \quad$ reference collision load equal to $210 \mathrm{MN}$;

$E_{i m p} \quad$ energy to be absorbed by plastic deformations of the bow;

$L \quad$ length of vessel [m];

$m_{x} \quad$ mass plus added mass $(5 \%)$ with respect to longitudinal motion $\left[10^{6} \mathrm{~kg}\right]$;

$V_{0} \quad$ initial speed of vessel $[\mathrm{m} / \mathrm{s}]$.

With respect to the bow deformation, the maximum indentation $s_{\max }$ is estimated from the equation of motion by approximating the load-indentation curves into sinusoidal curves:

$$
s_{\max }=\frac{\pi}{2} \cdot \frac{E_{\text {imp }}}{P_{\text {bow }}}
$$

and the associated impact duration derived from the equation of motion is estimated by

$$
T_{0} \approx 1.67 \cdot \frac{s_{\max }}{V_{0}}
$$

As for the bow type, according to statistical data sorted by Nielsen (1995), 40-50\% of merchant vessels have bulbous bows and the others have conventional bows. It is clear that bulbous bows produce higher crushing loads than the conventional ones due to their greater stiffness increased by the bulb. It should be noted that the above studies assumed rigid platform structures in predicting the impact force and bow structure deformations.

\subsection{Deformation of tubular members subjected to lateral loads}


Offshore platform structures are often made of tubular members and tubular members often have very thin walls when compared to the diameter. Therefore their deformations under ship impact, which will contribute to energy dissipation, are often significant and cannot be neglected. In previous studies, the tubular members are usually treated as thin-walled structures, allowing simplified equations to be employed to predict their responses in terms of the cross-sectional area, section modulus or plastic moment. The behavior of tubular members under lateral loads has been studied either via numerical, experimental or analytical approaches. Furnes and Amdahl (1980) defined the relationship between the indenting force and the depth of penetration and energy as:

$$
\begin{gathered}
P=15 m_{p}(D / t)^{1 / 2}(2 X / D)^{1 / 2} \\
E=14 m_{p} X^{1.5} / \sqrt{t}
\end{gathered}
$$

where

$m_{p} \quad$ plastic moment of the tube wall $\left(m_{p}=\left(t^{2} \cdot \sigma_{y}\right) / 4\right)$;

D tube diameter;

$\mathrm{t}$ tube wall thickness;

$\mathrm{X} \quad$ indentation depth;

$\sigma_{Y} \quad$ yield stress.

Figure 2 describes the approximated deformed surface caused by ship sideway impacts.

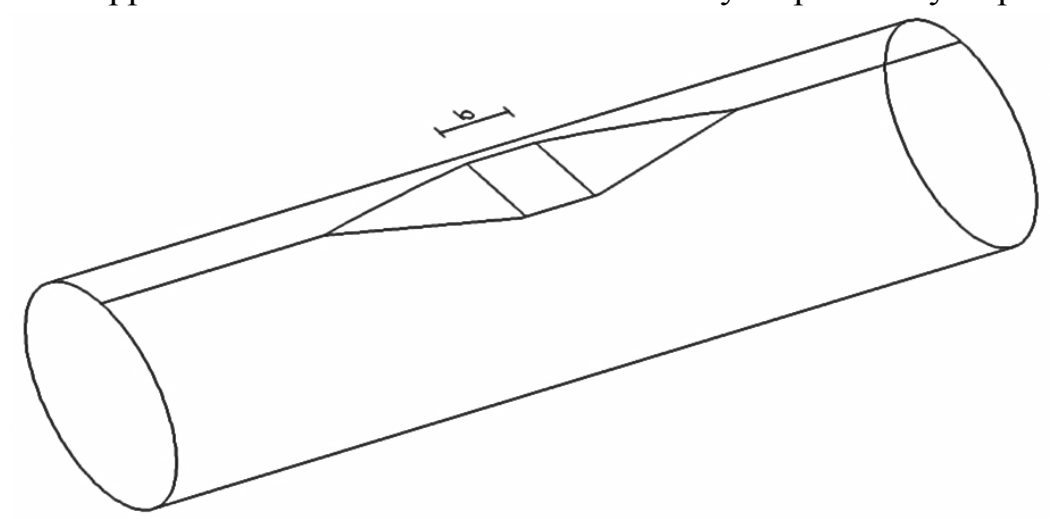

Figure 2. Plastic mechanism for sideway impact by supply vessel (Furnes and Amdahl, 1980) - b defines the length of the flattened area in contact with the indenter

A series of experiments by Ellinas and Walker (1985) were also performed to study the deformation phenomenon, including a constant coefficient, $K$, which stands for the shape of the indenter (normally assumed as 150):

$$
\begin{gathered}
P=\frac{K}{4} \sigma_{Y} t^{2}\left(\frac{X}{D}\right)^{1 / 2} \\
E=100 m_{p} X^{1.5} / \sqrt{D}
\end{gathered}
$$

The above two relations for the indenting force match one another when $D / t$ is equal to 50 . The main difference resides on the shape of the indenter which is a wedge-shaped or a rigid beam. It is assumed 
that the motion of the indenter towards the tube makes a right angle. It should be noted that the indenting force defined by Eq. (7) and (9) are derived without considering the interactions between ship structure and tubular members during the collision.

One of the first reports that can be found on the behavior of tubular members under dynamic lateral load belongs to Soreide and Kavlie (1985), who performed tests on tubes with time-dependent lateral concentrated loads. The response of the preloaded tubular members under lateral dynamic loads was studied by Zeinoddini et al (1999), through a series of numerical and experimental tests. All these studies had in common the fact that the lateral loads are applied at the mid-span of member. The effect of impact location along different points of the tube length on tubular member responses was addressed by Khedmati and Nazari (2012) by numerical simulations. These works that deal with the behavior of dented tubular members have two things in common: the indenters used to penetrate the tubes are rigid and the contact is made through a continuous contact surface.

When a tubular member subjects to relatively low velocity ship impact, its deformation consists of local denting and global bending. For tubular beams undergoing large deformations the global bending response is estimated using the three-hinge mechanism (Oliveira, 1981), which is based on the principle of virtual works. The load is modeled as a concentrated load and the method is best applied to braces due to their oblique position and thus an only single zone of contact. This assumption is also acceptable for stern impacts or early stages of broadside impacts where the contact with the platform happens at the ship deck or bilge due to rolling. The relation between concentrated impact load and the mid span deflection is

$$
\frac{P}{P_{u}}=\left\{\begin{aligned}
\sqrt{1-\left(\frac{U}{D}\right)^{2}}+\frac{U}{D} \sin ^{-1} \frac{U}{D}, & \frac{U}{D} \leq 1 \\
\frac{\pi}{2} \cdot \frac{U}{D}, & \frac{U}{D}>1
\end{aligned}\right.
$$

where

$U \quad$ central deflection at the point of impact

D tube diameter

$P_{u} \quad$ plastic collapse load of a circular tube with wall thickness $\mathrm{t}$ in pure bending

$$
P_{u}=\frac{8 M_{u}}{l}=\frac{8 \sigma_{u} D^{2} t}{l}
$$

This assumption is valid as long as there is no buckling of the tube wall and the full plastic capacity of the cross section can be achieved during the deformation.

The DnV current design practice (2010) makes use of Amdahl's methodology, which takes into account the effects of axial flexibility and the strength of the connections. The axial stiffness of the adjacent structure is replaced by discrete elements (Figure 3). When collisions do not occur at the center of the member, the force-deformation relationship can also be easily worked out. 


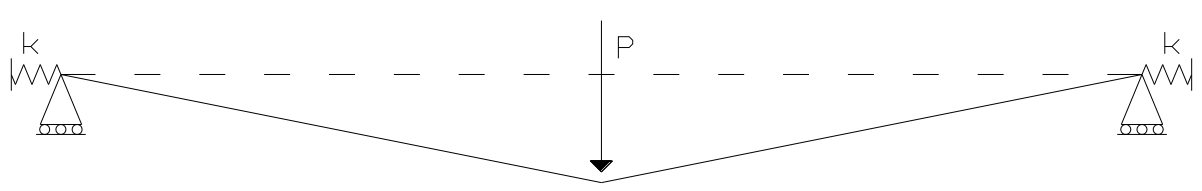

Figure 3. Force-deformation relationship for tubular beams with axial flexibility (DnV)

The local effects such as capacity reductions due to indentation and local buckling of tube wall can be considered by a deformation model at the point of impact. This modification is necessary when the wall thickness is not sufficient to avoid local denting (thinner walls may also allow the occurrence of local buckling). It is based on the assumption that the indented area is flat and the remaining part of the cross section has a constant radius of curvature. The reduced plastic section modulus can be derived by simple integration over the deformed cross section.

As discussed, all the above approaches neglect interactions between ship and tubular structure during impact, and either ship structure or tubular structure is assumed as rigid when calculating the responses of another structure. Recent studies of barge impacts on RC bridge piers found that the impact force and structural response depend on the bridge pier stiffness and geometry since dynamic interaction during barge impact and plastic deformations of the barge bow structure and bridge pier have significant influences on the impact loadings and structural responses (Sha and Hao 2012, 2013a, b). Since tubular structures in offshore platforms are usually more flexible as compared to RC bridge piers, relatively large deformation is expected under ship impact. Therefore it is important to take into consideration the deformation and interaction of both ship and platform structures to derive more accurate predictions of impact loadings and dynamic responses and damage of platform structures. In this study detailed numerical model is developed in LS-DYNA and intensive numerical simulations are carried out to investigate the influences of various structural parameters on impact loads and structural responses.

\section{Description of the defined model for numerical simulations}

\subsection{Ship}

The Norwegian Petroleum Directorate used to require platforms to be designed for impacts from supply vessels of 5000 ton of displacement with a speed of $2 \mathrm{~m} / \mathrm{s}$ (added mass effects are included). This yields a kinetic energy of $11 \mathrm{MJ}$ (added mass estimated in $10 \%$ for surge) for bow/stern impacts when specified values for hydrodynamic added mass are taken into account. According to Visser (2004), vessel displacements have been increased since 1985 to 6000 ton displacement and Central North Sea and Southern North Sea structures have been subjected to collisions involving ships up to 10000 ton. Amdahl and Johansen (2001) obtained force deformation for strength design of jacket legs against bow collisions of vessels with displacements comprised between 2000-5000 tons and the kinetic energy up to approximately 50-55 MJ (velocities up to $6 \mathrm{~m} / \mathrm{s}$ displacement of 3000 tons), which is currently used by the DnV code for the design of bow deformation and energy absorption within the mentioned displacement range. By assuming the inertia effects to be too small for the vessel speeds considered, the impact force for strength design could be estimated according to the crush depth of the bow.

In this study, the model of the ship proposed for numerical experiments is developed to give a good characterization of loading, deformation behavior and energy distribution that could be expected in a 
real impact scenario. Therefore, it is essential that the bow structure has a reasonable level of detail. Aspects such as crushing and rupture as well as buckling and plasticity are of important concerns. The finite element model of the bow is shown in Figure 4 which replicates to some extent the model of Amdahl and Johansen. It represents a generic model that can be considered representative for vessels in the range of 2000-5000 ton displacement. Since any possible kinetic energy to be absorbed by the ship is dissipated through the deformation of the very front part, the rest of the body has just been given the real outer shape in order to keep the ship dimensions and respective inertia properties in the numerical model (one must note that Equation 4 takes the vessel length into account for the estimation of the bow force).

The bow is modeled by a set of shell elements. Thickness values of $11 \mathrm{~mm}$ and $9 \mathrm{~mm}$ are in a first stage assumed for the shell plating and deck plating (average thickness) respectively. Interior scantlings such as forecastle deck, inner decks, frames and girders have been modeled accurately. The stiffness of the ship bows can vary between different manufacturers and ship types because of different layouts of internal reinforcement and variation of plate thickness. Nevertheless, the detail modeled part is expected to provide a reasonable accuracy on the estimation of the crushing forces. In (Paik, 2007), the crushing and rupture behaviors in ship collisions are analyzed through FE simulations. A good agreement is later shown in (Paik, 2007) between the FE results and experimental test models. In Figure 5 the true stress strain curve of a piece-wise linear, isotropic hardening material model, representative of the mild steel the ship can be made of, is estimated from the engineering stress-strain curve using the material model III defined by Paik (2007). This model is adopted in the present study to model the stress-strain relation of the steel material. The true stress-strain relationships can model the physical process with better accuracy than the engineering stress-strain relationships. This is because in situations such as the tensile test, the cross sectional area can change substantially and the engineering stress-strain definition ceases to be an accurate measure. Other values that characterize the mechanical properties of the steel used in the present study are $E=200$ $\mathrm{GPa}, \rho=7800 \mathrm{~kg} / \mathrm{m}^{3}$ and $v=0.3$.

The rear portion is modeled with solid elements with density in accordance with the intended total mass and mass distribution to be given to the ship. The description of the internal structure can be seen in Table 1. 


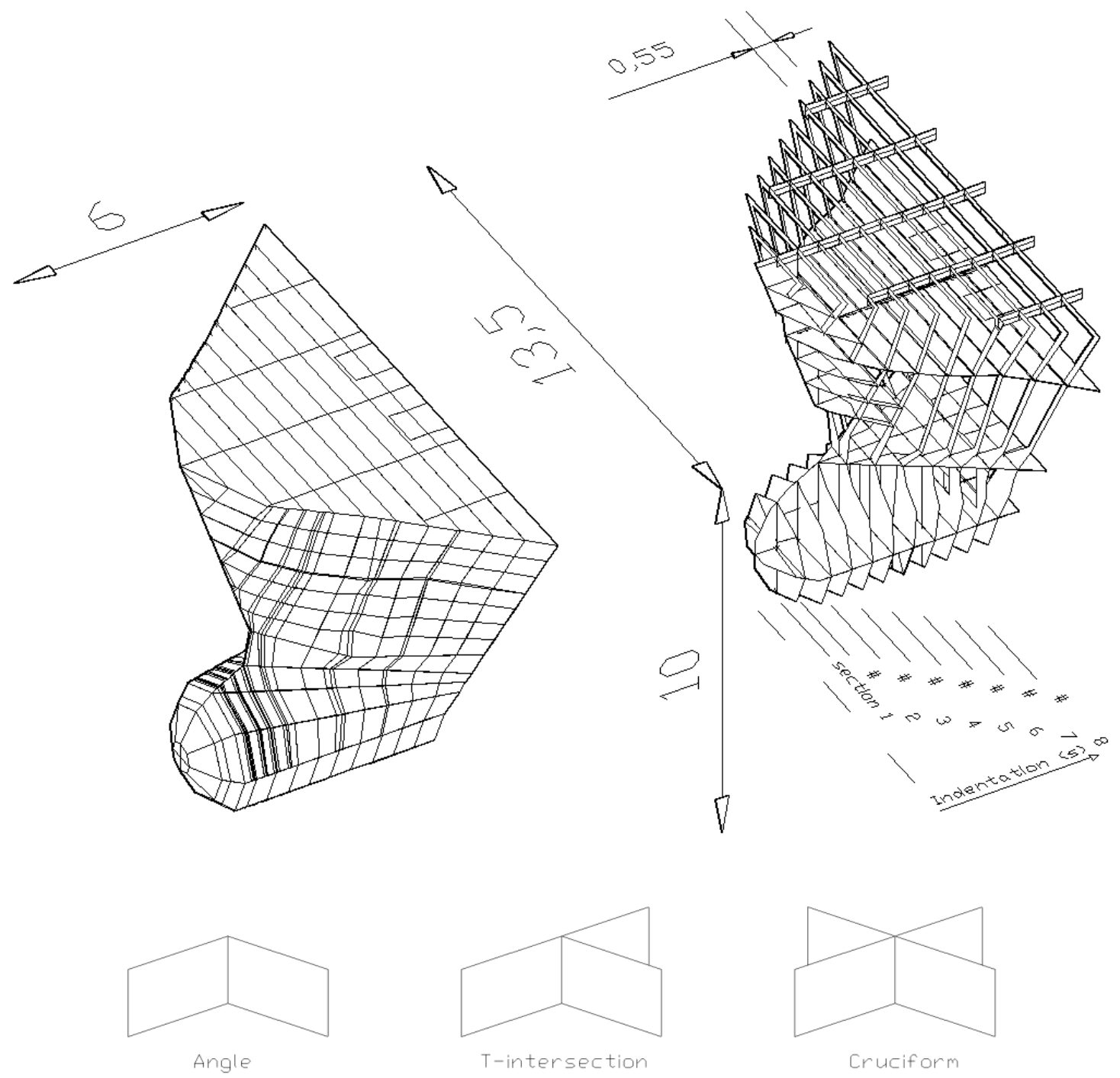

Figure 4. Bow model and internal layout (dimensions in meters)

Table 1. Bow structural features

\begin{tabular}{|l|c|c|c|}
\hline Shell thickness $[\mathrm{mm}]$ & 11 & \multicolumn{3}{|c|}{} \\
\cline { 1 - 2 } Plate thickness $[\mathrm{mm}]$ & 9 & \multicolumn{2}{|l|}{} \\
\hline Cross sections* & $\begin{array}{c}\text { Number } \\
\text { of angles }\end{array}$ & $\begin{array}{c}\text { Number of } \\
\text { T-sections }\end{array}$ & $\begin{array}{c}\text { Number of } \\
\text { cruciforms }\end{array}$ \\
\hline Section $1(\mathrm{~s}=0.55 \mathrm{~m})$ & 2 & 9 & 2 \\
\hline Section 2 $(\mathrm{s}=1.10 \mathrm{~m})$ & 2 & 11 & 3 \\
\hline Section $3(\mathrm{~s}=1.65 \mathrm{~m})$ & 4 & 12 & 4 \\
\hline Section $4(\mathrm{~s}=2.20 \mathrm{~m})$ & 2 & 13 & 5 \\
\hline Section $5(\mathrm{~s}=2.75 \mathrm{~m})$ & 2 & 14 & 1 \\
\hline Section $6(\mathrm{~s}=3.30 \mathrm{~m})$ & 2 & 9 & 1 \\
\hline Section $7(\mathrm{~s}=3.85 \mathrm{~m})$ & 2 & 11 & 1 \\
\hline Section $8(\mathrm{~s}=4.40 \mathrm{~m})$ & 2 & 11 & 1 \\
\hline
\end{tabular}

*Number of plate intersections according to Amdahl's procedure (as in Figure 1) 


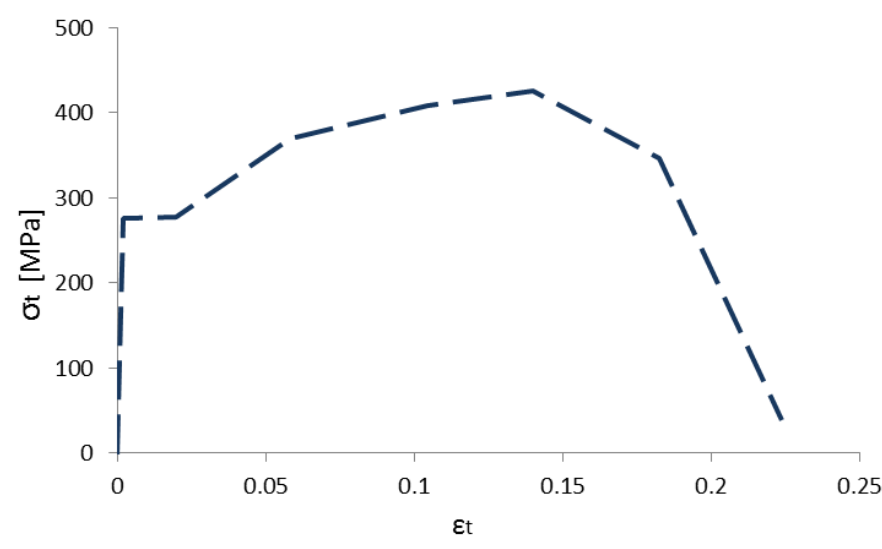

Figure 5. Estimated true stress-strain curve for ship material

The Cowper-Symonds relation (1967) can be adopted by the solver for the piecewise linear plasticity material to model the strain rate effect, which is given as follows:

$$
\frac{\sigma_{0}^{d}}{\sigma_{0}}=1+\left(\frac{\dot{\varepsilon}}{C}\right)^{1 / P}
$$

where $\sigma_{0}^{d}$ is the dynamic flow stress, $\sigma_{0}$ is the static flow stress and $C$ and $P$ are constants in the strain rate hardening law. The way how these parameters affect the system response is discussed in section 5.5.

The Overseas Coastal Area Development Institute of Japan reports the following relationship between the displacement tonnage (DT) and the deadweight tonnage (DWT):

$$
\left.\begin{array}{l}
\text { Cargo ships (less than } 10000 \text { DWT }): \log (D T)=0.550+0.899 \log (D W T) \\
\text { Cargo ships }(10000 D W T \text { or more }): \log (D T)=0.511+0.913 \log (D W T) \\
\text { Container Ships: } \log (D T)=0.365+0.953 \log (D W T) \\
\text { Roll on Roll off vessels: } \log (D T)=0.657+0.909 \log (D W T) \\
\text { Oil tankers: } \log (D T)=0.332+0.956 \log (D W T)
\end{array}\right\}
$$

According to the above relations, a mass of 3000 ton displacement and the bow dimensions of the chosen model nearly matches a 2000 DWT vessel which, according to the same source, would have an overall length (L) estimated in $83 \mathrm{~m}$ for a cargo ship or $76 \mathrm{~m}$ for an oil tanker.

\subsection{Tubulars}

Tubular members used in offshore steel structures have their response to lateral loading influenced by their geometrical and mechanical properties and external conditions such as axial pre-loading or stiffness of the adjacent members and connections. The pipe members used for numerical calculations are modeled with shell elements of size $100 \mathrm{~mm}$. The mechanical and geometrical properties as well as other parameters regarding the tubes external conditions considered in the numerical tests are shown in Table 2 and Table 3:

Table 2. Mechanical properties of the steel tubular members used in numerical tests

\begin{tabular}{|c|c|c|c|c|c|}
\hline $\mathrm{E}(\mathrm{Gpa})$ & $\sigma_{\mathrm{y}}(\mathrm{Mpa})$ & $\sigma_{\mathrm{u}}(\mathrm{Mpa})$ & $\varepsilon_{\mathrm{u}}$ & $\mathrm{V}$ & $\rho\left(\mathrm{Kg} / \mathrm{m}^{3}\right)$ \\
\hline 200 & 250 & 385 & 0.15 & 0.3 & 7800 \\
\hline
\end{tabular}


Table 3. Geometric dimensions and external conditions of tubes numerically tested

\begin{tabular}{|c|c|}
\hline Parameter & Values/Description \\
\hline Diameter, D $(\mathrm{m})$ & $1.5,2$ \\
\hline Thickness, $\mathrm{t}(\mathrm{mm})$ & $40,50,60,80$ \\
\hline Length, L $(\mathrm{m})$ & $0 \%, 50 \% F_{a}$ \\
\hline Axial preloading & $15,18,18.5,21,22,24,26,27,30$ \\
\hline Boundary conditions & Fixed ends, Pinned ends \\
\hline Strain rate effects & Neglected/Included \\
\hline
\end{tabular}

\section{Numerical model calibration}

\subsection{Bow mesh size}

In order to verify the reliability of the bow model, the elements comprising the two parts of the ship (bow and rigid blocks) have been developed in LS-DYNA and performed impacting simulations by assuming an impacting speed of $6.0 \mathrm{~m} / \mathrm{s}$ towards a rigid cylinder with a diameter of $2 \mathrm{~m}$ and a rigid wall, respectively. The density of the solid blocks has been adjusted such that the whole mass of the rear part could make up 3000 ton. Together with the ship bow structural elements, the initial kinetic energy is estimated as 54 55 MJ.

Convergence tests are performed to verify the mesh density of the shell elements. These tests are performed assuming the impact with the rigid tube. The explicit dynamic analyses are carried out using the computer code LS-DYNA. To model the impact and the deformations, two contact algorithms are chosen: the keywords AUTOMATIC_SURFACE_TO_SURFACE, for the slave surface (ship bow elements) hitting the master surface (cylinder), and AUTOMATIC_SINGLE_SURFACE, that prevents the bow elements free penetration when large deformations occur. This is because when the penetration of the cylinder into the ship bow takes place, it is likely that some of the structural elements of the ship will touch one another and so the secondary stiffness of the bow is restored. If this is disregarded, the crushing force could have been underestimated. The shell elements have initially been tested with sizes of $0.1 \mathrm{~m}$ and $0.05 \mathrm{~m}$ (see Table 4). As shown in Figure 6 , the both element sizes lead to very similar predictions, but simulation time is greatly reduced if $0.1 \mathrm{~m}$ element is used although the required simulation time is still substantial. Because the time-step of the explicit numerical analysis drops during the contact, making the total calculation time very long, to further reduce the calculation time the mass scaling technique is adopted. The addition of a non-physical mass to the structure to achieve a large time-step affects the results owing to additional inertial force $\left(F=m^{*} a\right)$. By trying to limit the time step to $1 \mathrm{E}-6$ for a shell element size of $0.1 \mathrm{~m}$, it is observed that (see 0.1 'case in Figure 6) the error in the calculated impact force owing to the additional non-physical mass never goes over $0.1 \%$ as compared to that without using mass scaling technique, but using this technique leads to further significant reductions in computation time.

Table 4. Meshes used for convergence tests

\begin{tabular}{|c|c|c|}
\hline Shell element size (m) & Total number of shell elements & $\begin{array}{c}\text { Calculation time factor } \\
\text { (approximation) }\end{array}$ \\
\hline $0.1^{\prime}$ ' (mass scaling) & 64620 & 1 (between 7-10 hrs) \\
\hline 0.1 & 64620 & 3 \\
\hline 0.05 & 238012 & 60 \\
\hline
\end{tabular}



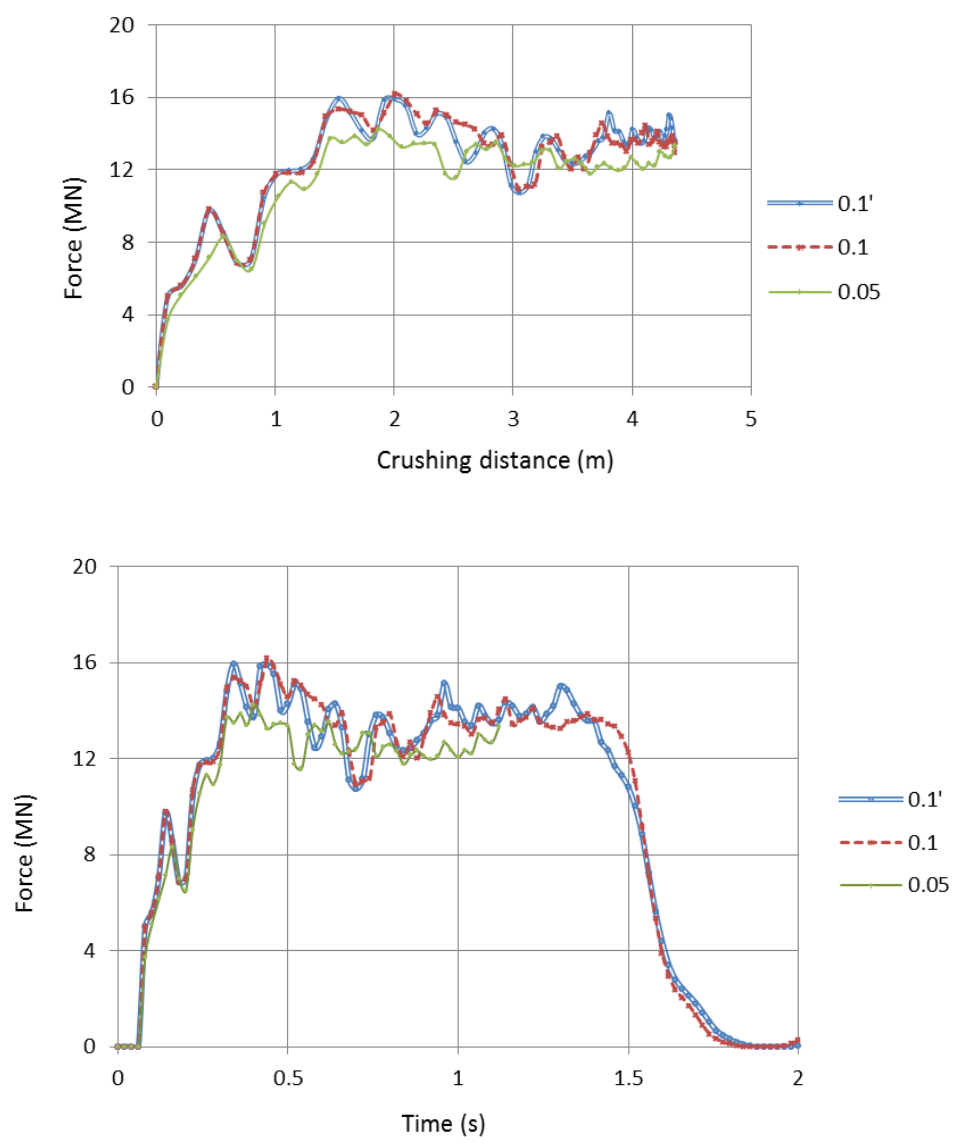

Figure 6. Comparison of ship bow shell element size

Considering the simulation time and CPU costs, the use of mass scaling techniques and $0.1 \mathrm{~m}$ shell elements is adopted in this study.

\subsection{Bow crushing force}

The comparison between deformations on bows caused by a 'rigid jacket leg' and a rigid wall and Equation 1 are shown in Figure 7. The design curve currently used in the DnV design code recommended for vessels within the range of 2000-5000 tons against jacket legs with diameters between $1.5 \mathrm{~m}$ and $2.5 \mathrm{~m}$ and kinetic energy up to $60 \mathrm{MJ}$ for bow collisions, is also plotted.

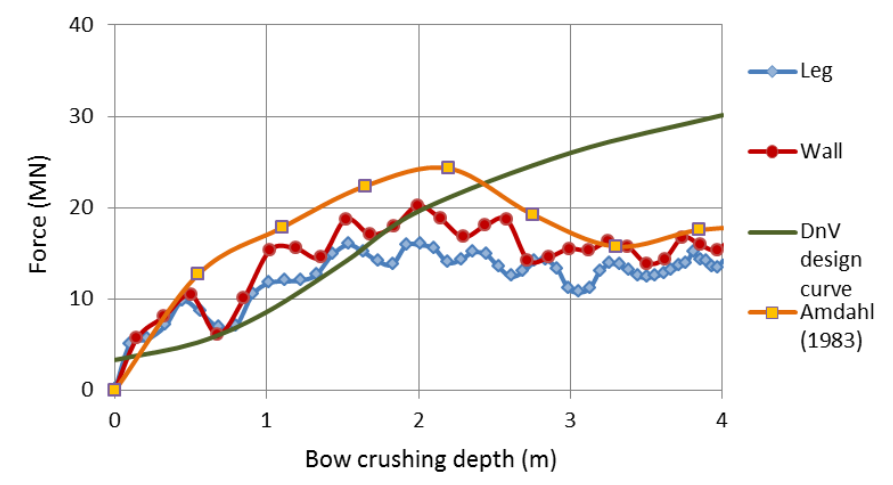

Figure 7. Force-Indentation curves of theoretical approaches and LS-DYNA explicit dynamic simulations 
It can be seen that, despite a bit conservative, Amdahl's prediction based on Equation 1 shows the same trend as the FE results. If compared to the design curve used in the DnV code, the values of the FE calculations are higher until the maximum force point. It must be noticed that several types of ships can come across offshore platforms and their internal structure varies in many ways and so does their geometry. Equation 1 takes into account parameters such as the spacing between longitudinal frames, thickness of structural elements or areas of the cross sections, but not the colliding structure. Between the collisions with a rigid cylinder and a rigid wall, the expected small reduction in the contact force when colliding with a cylinder can be observed in the figure. The snapshots of the two cases are illustrated in Figure 8 at different stages of impact:

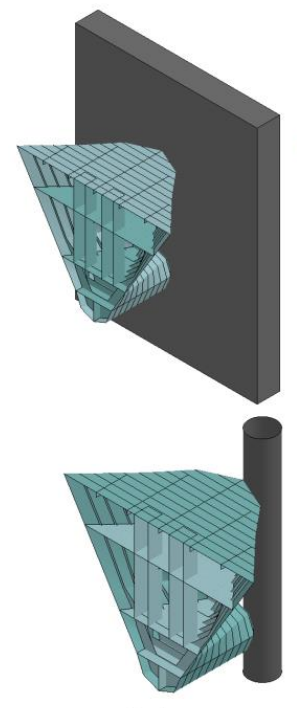

$\mathrm{T}=0 \mathrm{~s}$
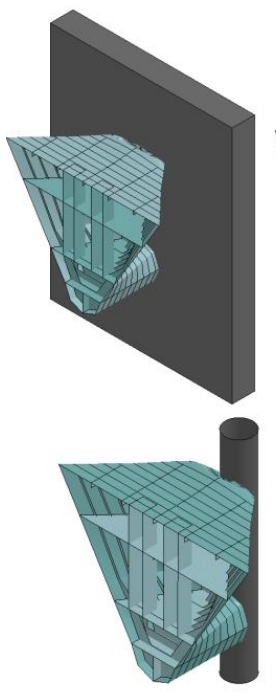

$\mathrm{T}=0.2 \mathrm{~s}$
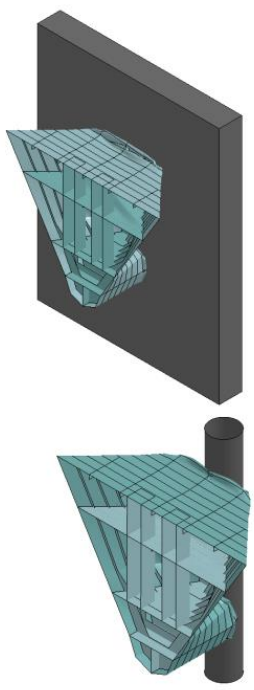

$\mathrm{T}=0.4 \mathrm{~s}$
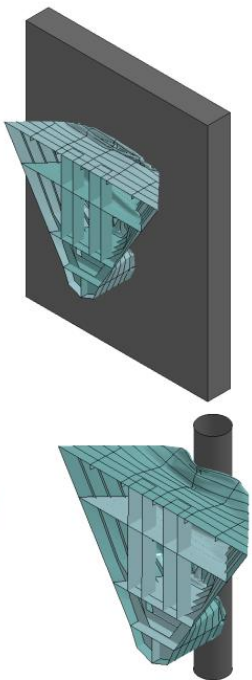

$\mathrm{T}=0.6 \mathrm{~s}$

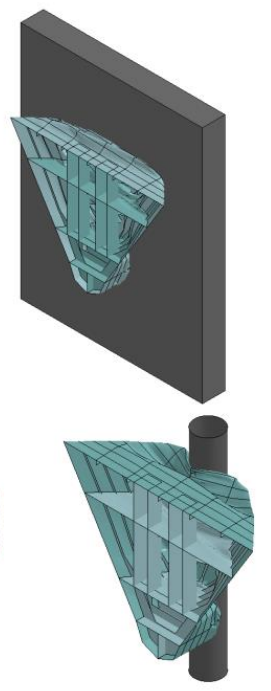

$\mathrm{T}=0.8 \mathrm{~s}$

Figure 8. Deformation of bulbous bow at different time-steps

The 2000 DWT tanker model used by Pedersen (1992) to estimate bow crushing loads on a rigid wall, at an initial speed of $7 \mathrm{~m} / \mathrm{s}$, is compared in Figure 9 . The contact force for bow with bulb from the $\mathrm{DnV}$ is also plotted:

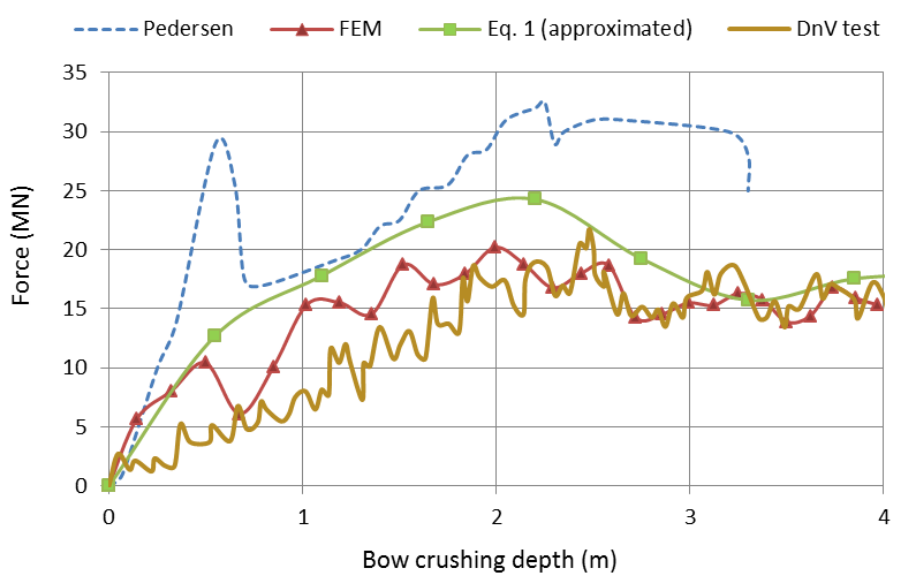

Figure 9. Force-Indentation curves against a rigid wall

As shown, the use of Pedersen's tanker model results in higher prediction of impact force. The peak impact force registered of nearly $30 \mathrm{MN}$ before the denting reaches $1 \mathrm{~m}$ with Pedersen's model can be explained by a possible different internal layout of the model. Also, the plate thickness of the 2000DWT ship hull ranges from 8.5 to $18.0 \mathrm{~mm}$, giving a higher plate thickness average than the 11.0 
$\mathrm{mm}$ used in the current model. This consequently results in a more rigid bow structure, less plastic deformation, less energy absorption and greater exerted force by the bow.

Following Equation 4, the maximum bow force $P_{\text {bow }}$ of a 2000 DWT cargo ship colliding with a rigid wall with an initial speed of $6 \mathrm{~m} / \mathrm{s}$ would be $51.5 \mathrm{MN}$, dropping to $46.5 \mathrm{MN}$ in the case of the 2000 DWT oil tanker, substantially higher than the $20.2 \mathrm{MN}$ predicted by the FEM calculation or the 24.3MN predicted by Equation 1. Although Equation 4 accounts for effects such as the strain rate of the steel, and the size of the ship is similar to the model considered in this study, the ship models considered in deriving the equation are made of thicker plates and different steel mechanical properties. These differences result in different predictions of impact forces.

\subsection{Tube deformation}

Tubular members used in offshore steel structures have their response to lateral loading influenced by their geometrical and mechanical properties and external conditions such as axial pre-loading or stiffness of the adjacent members and connections. Their response to lateral impacts also depends on the type of the indenter they are subjected to during penetration. To compare the response of steel pipes when impacted by rigid indenters of different sizes (different contact areas are implied), three clamped tubes modeled with shell elements are considered. The three cases are described in Table 5. The mechanical properties are the same as those described in Table 2. For all the cases the behavior of the tubes after yielding is defined as fully plastic and the influence of the strain hardening is compared for case $\mathrm{C}$. Two different rigid indenters of different sizes are modeled for penetration. Both indenters have cubic shapes, with the larger one being ten times wider than the thinner one. They give a contact length along the longitudinal direction of the pipe of $0.2 \mathrm{~m}$ and $2 \mathrm{~m}$ respectively, or $2 \%$ and $20 \%$ of the full length of the tube A. In simulations, a vertical prescribed motion of $0.5 \mathrm{~m} / \mathrm{s}$ is given to the indenters, downwards to the tube that is horizontally positioned (see Figure 10).

Table 5. Numerical data for tubulars statically loaded by different rigid size indenters

\begin{tabular}{|l|c|c|c|c|c|}
\hline Tube & $\mathrm{L}[\mathrm{m}]$ & $\mathrm{D}[\mathrm{m}]$ & $\mathrm{t}[\mathrm{mm}]$ & $\mathrm{L} / \mathrm{D}$ & $\mathrm{D} / \mathrm{t}$ \\
\hline A & 10 & 1.5 & 30 & 6.7 & 50 \\
\hline B & 10 & 1.5 & 43 & 6.7 & 34.9 \\
\hline C & 20 & 1.5 & 43 & 13.3 & 34.9 \\
\hline
\end{tabular}

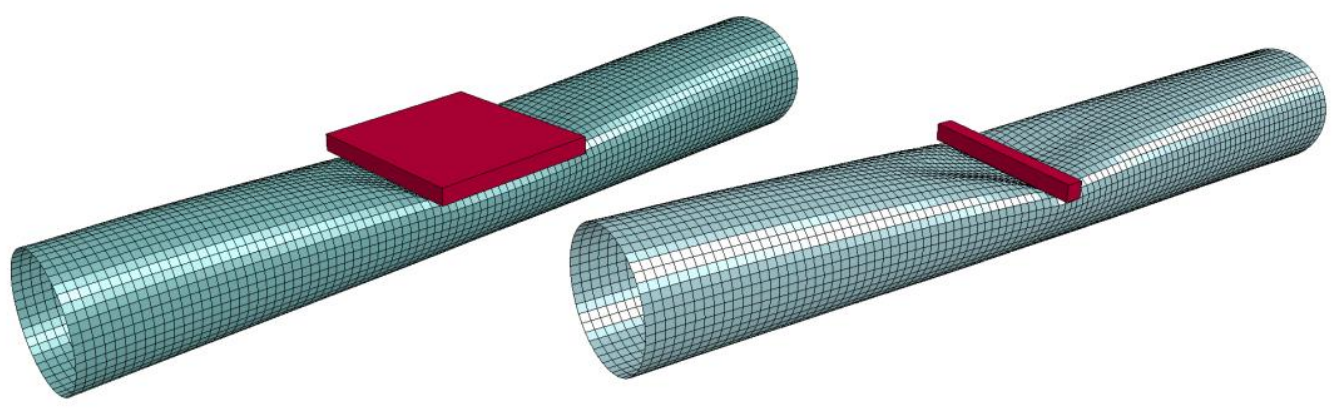

Figure 10. Deformation shape of tubular members subjected to impacts from different indenters

Experimental impact tests reported in Jones and Birch (1996) conducted on pressurized mild steel pipes with clamped ends have shown, for $D / t$ ratios of 35.3 and a $L / D$ proportion of 10 , that the semiempirical predictions from Equation 9 would better agree with their experimental results if $K$ was taken as twice as the empirical value adopted by Ellinas and Walker (1985), i.e. $K=300$. However, 
Jones and Birch (2009) consider $K=150$ valid for $X / t$ values up to 5.8, which approximately corresponds to the case when the local denting deformation stops and the global displacement takes place. The displacement values of the numerical tests are recorded and plotted in Figure 11 until failure. As shown, for the ultimate strain defined in Table 2, the total deflection values obtained prior to failure of the shell elements are relatively small when compared to those predicted by Equation 9 with $\mathrm{K}=300$. It is obvious in Figure 11 that the prediction with $K=150$ shows a reasonable agreement for both $D / t$ values for the thin striker. In fact, neither in case A nor in case B global deflection has been detected. For tube $\mathrm{C}$, the increase of the tube length provokes a very small drop in the contact force for the same deformation value, and very small displacements of the lower membrane are observed. The effects of the strain hardening are also compared in Figure 12, where it is clear that their inclusion in the material properties will not significantly affect the tube response, except for the tube failure at higher deflection values possibly due to the higher capacity of rotation of the plastic zone.

The results for the penetration using the larger indenter lie in between the curves for $K=150$ and $K=300$, indicating the indenter size will influence the response as it changes the contact area between striker and struck tube.

Currently, the DnV (2010) resistance curves for local denting predict the variation of the flattened contact area through the use of constants that take into account the ratio between the length of the flattened surface and the diameter of the tube. The comparisons of the DnV curves with the numerical tests for tubes A and B using the two indenters show an acceptable agreement in Figure 13.
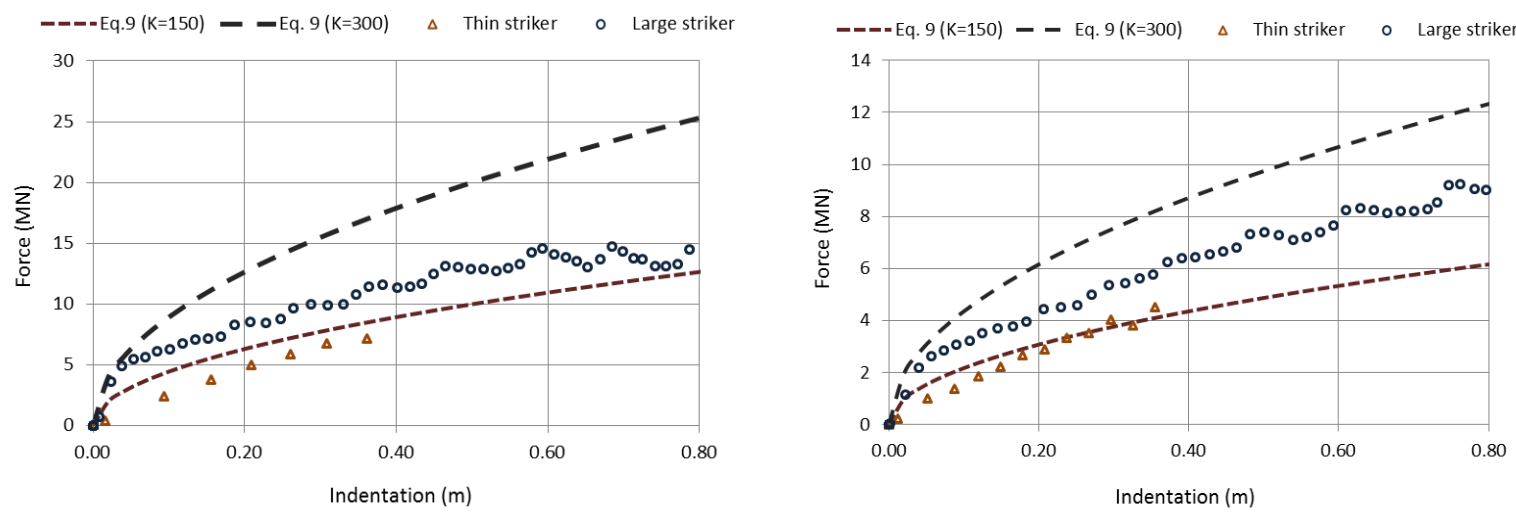

Figure 11. Force deformation curves, comparison with Equation 9 (Left: $\mathrm{D} / \mathrm{t}=50$; Right $\mathrm{D} / \mathrm{t}=35$ ) 


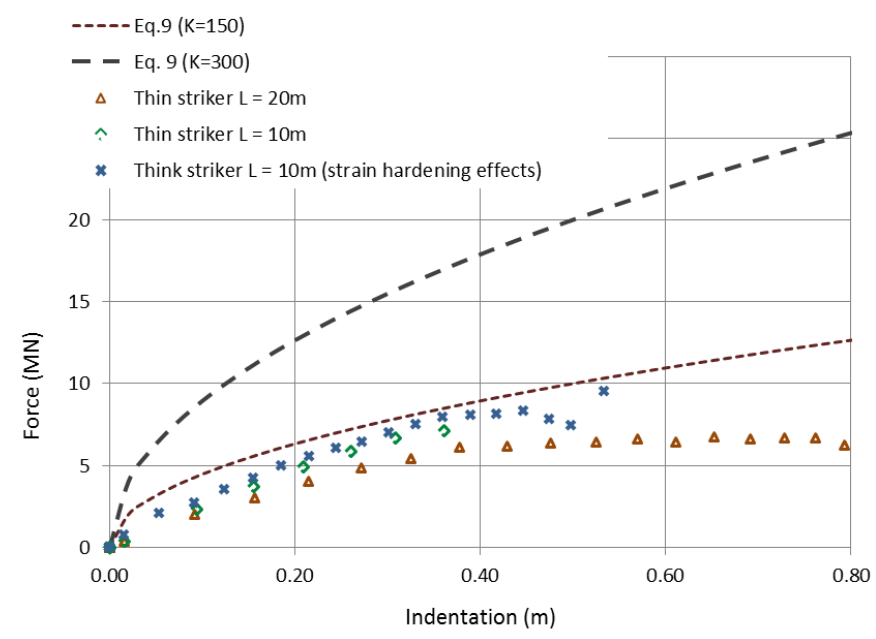

Figure 12. Force deformation curves for different tube length.
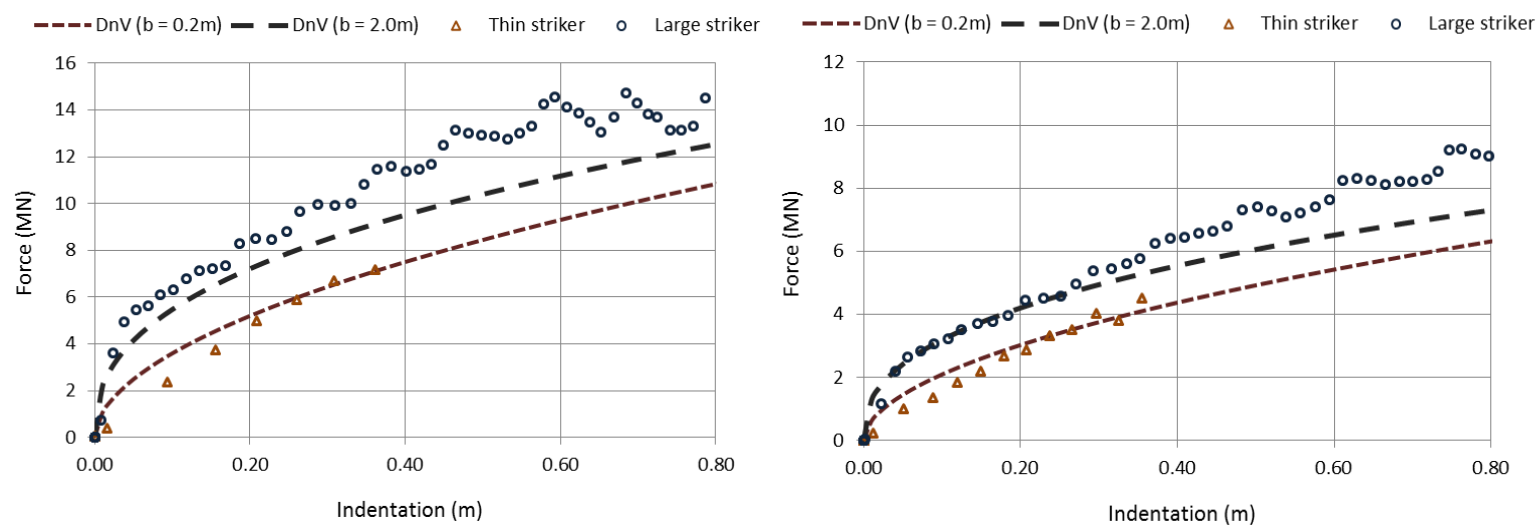

Figure 13. Force deformation curves, comparison with the DnV (2010) curves (Left: $D / t=50$; Right $D / t=35)$

To examine what the force-deformation behavior of a steel tube hit by a striker with an irregular shape such as a ship bow could be, the shell of the bow model is set as rigid with the rigid blocks that make up the ship rear part attached. The hit tube is given a diameter of $2 \mathrm{~m}$, with thickness and length of 40 $\mathrm{mm}$ and $10 \mathrm{~m}$ respectively. The steel properties are taken from Table 2 as well.

From the contact with a bulbous bow there are two main points of contact that may locally deform the tube wall: the region where the tube wall is hit by the bulb and the zone at the level of the forecastle deck. Due to the geometry and the areas in contact the bulb is responsible for the higher portion of the total contact force. The curve from the FE simulation is compared with the DnV force-deformation relationships for denting in Figure 14. 

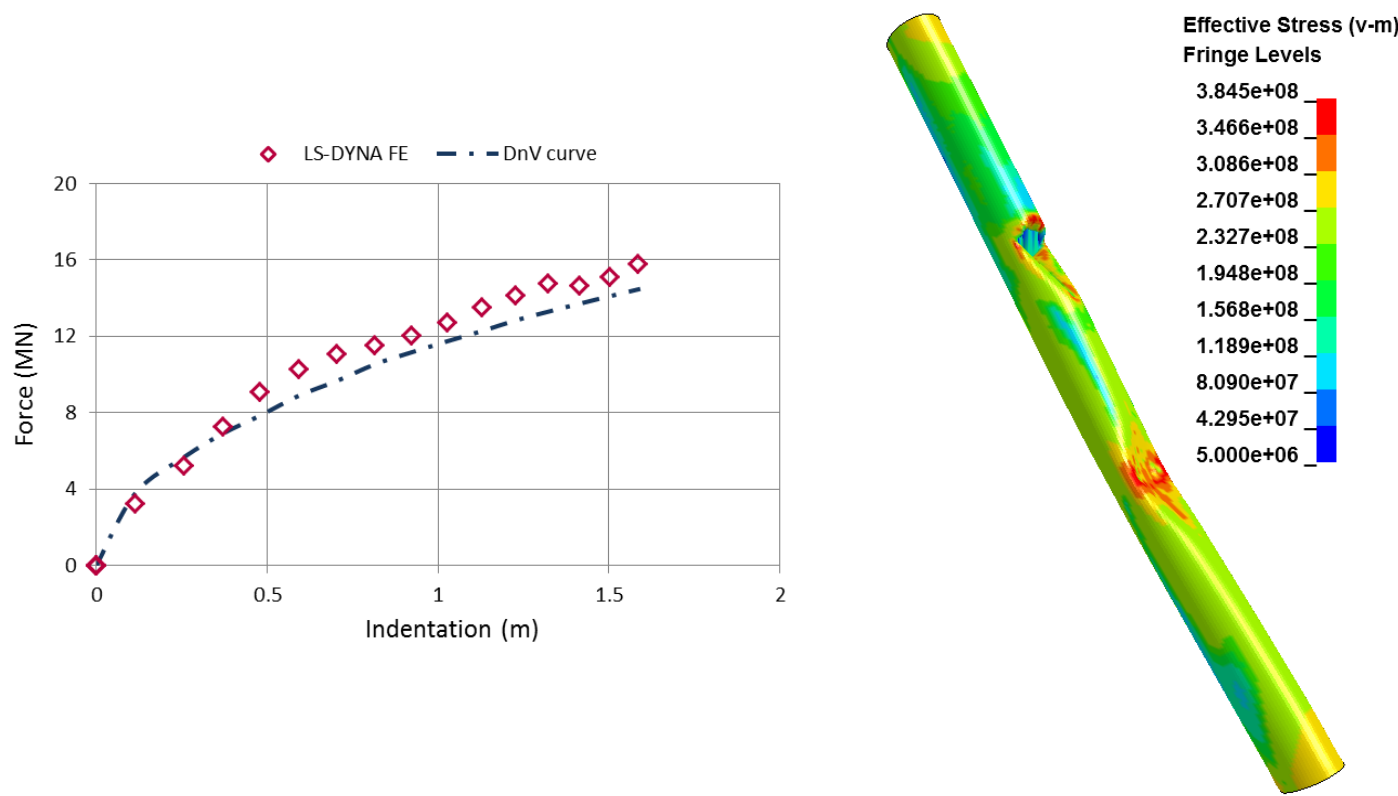

Figure 14. Tube deformation caused by penetration of rigid bulbous bow

As shown, the DnV estimation agrees well with the FE simulation until the denting reaches approximately $12-13 \%$ ( 0.24 to $0.26 \mathrm{~m})$ of the tube diameter. At this point, shear failure occurs at the upper contact point. This is justified by the sharpened bow shape at the top. In this particular case, the failure of the lower contact point happens when the indentation reaches around $75 \%$ of the diameter. It should be noted that these results are obtained with rigid ship bow assumption. In real case, the bows are not rigid and so the estimation of the contact force has also to consider the bow deformations. Nonetheless this observation demonstrates that the applicability of the design curves has to take into account two aspects: the indenter strength and the denting configuration. It must be noted that the scope of Equations 7 to 10 is based on broadside impacts that are likely to take place at mooring of supply vessels. The fact that head-on collisions involving bulbous bows can result in two distinct indentation areas relates the penetration force to a different denting configuration. The current practice assumes the deflection mechanism of the tube membrane similar to a nonlinear spring that considers the geometrical parameters referred in Equations 7-10. In Figure 14 the DnV design curve is obtained by considering the sum of the two contact points as the total contact area. It is not clear, however, what the error could be for different distances between the two contact points, which in some cases could result in interference between the two denting mechanisms. This issue, however, is not investigated in the present work, as the primary objective of the present study is to investigate the influences of ship and platform structure interaction during impact and the deformations of both ship and platform structures on impact loads and structural response and damage.

\section{Parametric investigation}

\subsection{Tube geometry}

The way how the energy is absorbed through the tubes depends on the nature of the deformation they are subjected to. Local denting and bending can interfere with one another during the deformation process. The damage caused by the local denting deformation of the tube wall is influenced by the global bending deformation and hence by the cross section geometry, tube length and boundary conditions. From Equations 7 and 9, it is obvious that the wall thickness of the tubes has a higher 
influence on the denting capacity than the diameter of the cross section. Considering the tube cross section diameter as $1.5 \mathrm{~m}$ and $2.0 \mathrm{~m}$ respectively, the denting resistance varies, according to Equation 9, by $15.5 \%$ for the same wall thickness and yield strength while according to Equation 7 it is not affected. On the other hand, the influence of thickness is included in both the expressions, being the resistance increased by factors of 2.83 (Equations 7 and 8) and 4 (Equations 9 and 10) with the thickness increasing from 40 to $80 \mathrm{~mm}$ for a given section diameter, implying significant differences in those formulae. The same mentioned factors obviously also affect the energy absorptions and according to these expressions the energy absorption through local denting is mainly related to the plastic moment of the thin walled tubes.

The distinction between local and global deformations on tubular members due to impact has rarely been reported in experimental studies, where the overall displacement is assessed rather than the contribution of each of the deformation modes. Jones and Birch (2009) estimated both local and global displacements from an idealized deformed cross section configuration described in Figure 15.

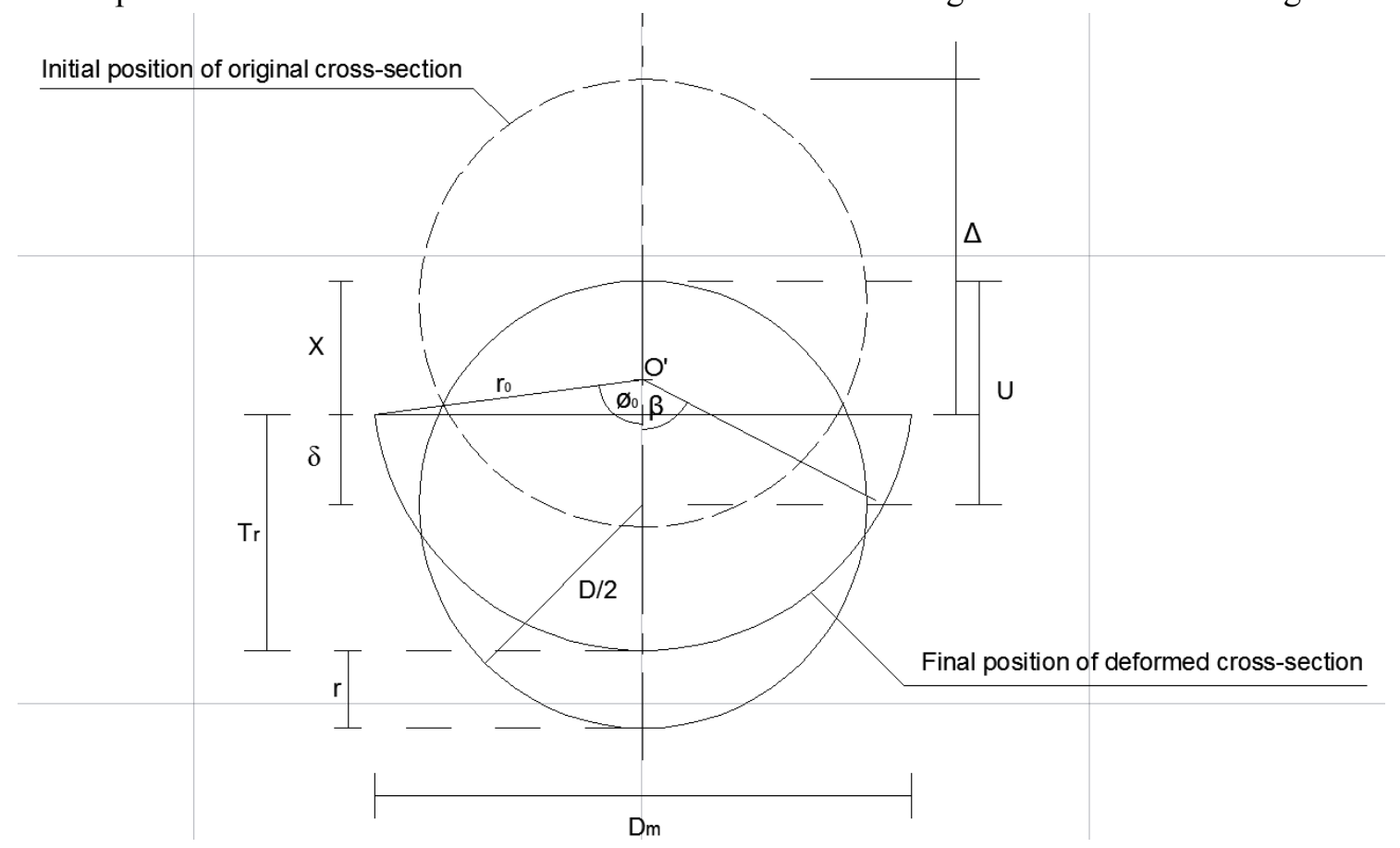

Figure 15. Definitions of the local denting $(\mathrm{X})$, global bending $(\mathrm{U})$ and total displacement $(\Delta)$ for the idealized deformed pipe section (Jones and Birch, 2009)

The following relationships can be assumed and compared to measurements from the impact test:

$$
\begin{gathered}
r_{0}=T_{r} \cdot\left[1+\left(D_{m} / 2 T_{r}\right)^{2}\right] / 2 \\
\beta=\pi D / 4 r_{0} \\
\cos \emptyset_{0}=1-T_{r} / r_{0} \\
\delta=r_{0}\left(\cos \beta-\cos \emptyset_{0}\right) \\
X=D / 2-\delta \\
U=\Delta-X
\end{gathered}
$$


in which $r_{0}$ is the radius of the deformed cross section, $T_{r}$ the local permanent thickness of the deformed cross section and $D_{m}$ the maximum width of the deformed cross section.

The graphic in Figure 16 relates the tube dimensions with the dominant deformation mode for different tubes with fixed ends after impact of the ship model described in 3.1. As a criterion, it has been considered that the cross sections undergoing deformations of less than $2 \%$ of their diameter is assumed as fully effective or rigid. Thus, for shorter and thicker members, the behavior can be assumed as practically rigid because of small local denting and global beam flexural deformations. This is verified by the numerical simulations of the cases where the member wall is $60 \mathrm{~mm}$ thick, and where the energy locally absorbed by the steel tubular wall is not higher than $\sim 2.5 \%$ of the impact energy ( $\sim 55 \mathrm{MJ})$ of the full system (ship and platform) system, i.e. less than $\sim 1.3 \mathrm{MJ}$. As shown in the figure, when $L / D$ ratio is large, flexural bending tends to dominate the tubular member deformation, while local denting deformation dominates when the $L / D$ ratio is small and member wall is thin.

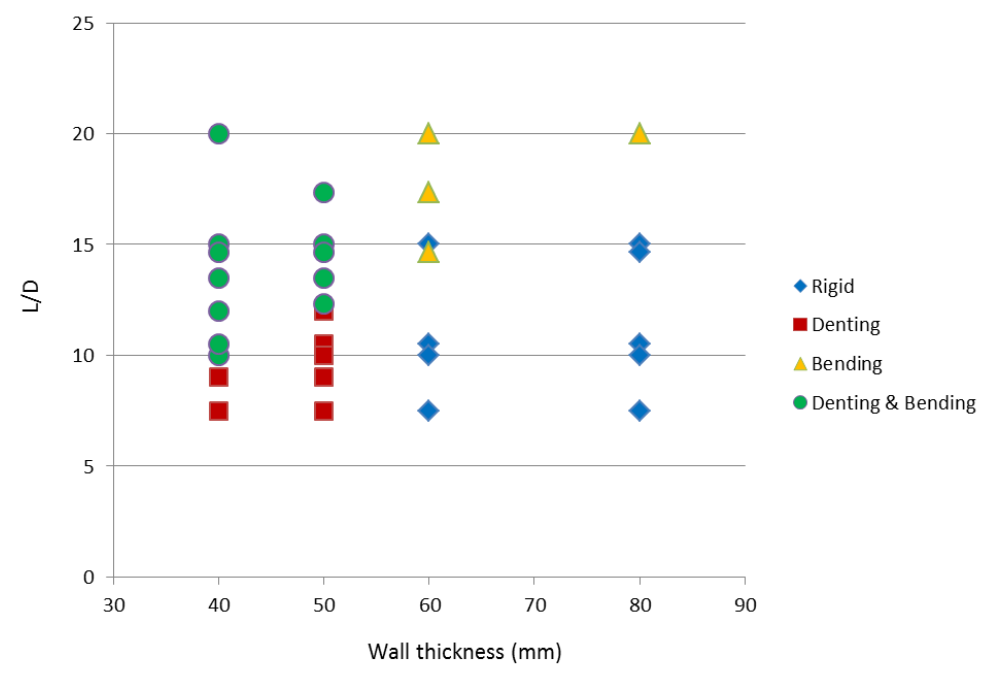

Figure 16. Deformation modes of tubes

The cases shown in Figure 16 are compared with those calculated by Equations 15-20 in Table 6. The calculated deformation value $X$ obtained by Equation 19 from the values $D_{m}, \Delta$ and $T_{r}$, measured from the numerical models after the impact, is compared with the same parameter $X$ directly taken from the numerical simulations. In Table 6 , D represents tube diameter, $t$ thickness and L length. For example, D2t40L15 represents a tube of diameter $2 \mathrm{~m}$, thickness $40 \mathrm{~mm}$ and length $15 \mathrm{~m}$. 
Table 6. Numerical results of fixed-ends steel pipe deformation after ship bow impact

\begin{tabular}{|l|c|c|c|c|c|c|c|c|c|c|c|c|}
\hline \multicolumn{1}{|c|}{ Test } & $\begin{array}{c}\mathrm{Tr} \\
{[\mathrm{m}]}\end{array}$ & $\begin{array}{c}\mathrm{Dm} \\
{[\mathrm{m}]}\end{array}$ & $\begin{array}{c}\mathrm{r}_{0} \\
{[\mathrm{~m}]}\end{array}$ & $\begin{array}{c}\mathrm{B} \\
{[\mathrm{rad}]}\end{array}$ & $\begin{array}{c}\phi_{0} \\
{[\mathrm{rad}]}\end{array}$ & $\begin{array}{c}\delta \\
{[\mathrm{m}]}\end{array}$ & $\begin{array}{c}\mathrm{X} \\
{[\mathrm{m}]}\end{array}$ & $\begin{array}{c}\mathrm{D} \\
{[\mathrm{m}]}\end{array}$ & $\begin{array}{c}\Delta \\
{[\mathrm{m}]}\end{array}$ & $\begin{array}{c}\mathrm{U} \\
{[\mathrm{m}]}\end{array}$ & $\begin{array}{c}\mathrm{X} \\
\text { (measured) } \\
{[\mathrm{m}]}\end{array}$ & $\begin{array}{c}\mathrm{E}_{\mathrm{s}} \\
{[\mathrm{MJ}]}\end{array}$ \\
\hline D2t40L15 & 1.418 & 2.138 & 1.112 & 1.413 & -0.275 & 0.481 & 0.519 & 2.0 & 0.551 & 0.032 & 0.582 & 5.37 \\
\hline D2t40L21 & 1.094 & 2.343 & 1.174 & 1.338 & 1.502 & 0.191 & 0.809 & 2.0 & 1.087 & 0.278 & 0.906 & 10.44 \\
\hline D2t40L30 & 1.141 & 2.410 & 1.207 & 1.302 & 1.516 & 0.255 & 0.745 & 2.0 & 1.730 & 0.985 & 0.859 & 15.67 \\
\hline D1.5t40L15 & 1.115 & 1.544 & 0.825 & 1.428 & 1.930 & 0.407 & 0.343 & 1.5 & 0.504 & 0.161 & 0.385 & 4.61 \\
\hline D1.5t60L22 & 1.461 & 1.500 & 0.923 & 1.276 & 2.193 & 0.806 & -0.056 & 1.5 & 0.290 & 0.346 & 0.039 & 3.20 \\
\hline D1.5t80L30 & 1.479 & 1.500 & 0.930 & 1.267 & 2.203 & 0.827 & -0.077 & 1.5 & 0.958 & 1.036 & 0.021 & 11.97 \\
\hline D2t50L15 & 1.781 & 2.030 & 1.180 & 1.332 & 2.106 & 0.881 & 0.119 & 2.0 & 0.021 & -0.098 & 0.219 & 1.10 \\
\hline D2t50L21 & 1.713 & 2.070 & 1.169 & 1.344 & 2.055 & 0.807 & 0.193 & 2.0 & 0.281 & 0.088 & 0.287 & 1.71 \\
\hline D2t50L30 & 1.532 & 2.17 & 1.150 & 1.366 & 1.909 & 0.616 & 0.384 & 2.0 & 0.468 & 0.084 & 0.468 & 6.64 \\
\hline D1.5t50L15 & 1.488 & 1.511 & 0.936 & 1.259 & 2.202 & 0.839 & -0.089 & 1.5 & 0.013 & 0.103 & 0.124 & 0.72 \\
\hline D2t40L18 & 1.207 & 2.300 & 1.151 & 1.364 & 1.619 & 0.292 & 0.708 & 2.0 & 0.793 & 0.085 & 0.829 & 7.80 \\
\hline D2t40L24 & 1.029 & 2.395 & 1.211 & 1.297 & 1.420 & 0.145 & 0.855 & 2.0 & 1.399 & 0.545 & 0.971 & 14.59 \\
\hline D2t40L27 & 0.880 & 2.501 & 1.328 & 1.182 & 1.226 & 0.055 & 0.945 & 2.0 & 1.938 & 0.993 & 1.120 & 20.55 \\
\hline D1.5t50L18.5 & 1.237 & 1.519 & 0.852 & 1.383 & 2.040 & 0.544 & 0.206 & 1.5 & 0.263 & 0.057 & 0.167 & 1.99 \\
\hline D2t50L27 & 1.651 & 2.103 & 1.160 & 1.354 & 2.007 & 0.741 & 0.259 & 2.0 & 0.468 & 0.209 & 0.349 & 3.61 \\
\hline D2t50L18 & 1.744 & 2.045 & 1.172 & 1.341 & 2.081 & 0.840 & 0.160 & 2.0 & 0.250 & 0.090 & 0.256 & 1.39 \\
\hline D2t50L24 & 1.699 & 2.060 & 1.162 & 1.352 & 2.051 & 0.789 & 0.211 & 2.0 & 0.348 & 0.137 & 0.301 & 2.32 \\
\hline D1.5t60L26 & 1.331 & 1.566 & 0.896 & 1.315 & 2.078 & 0.662 & 0.088 & 1.5 & 1.064 & 0.976 & 0.169 & 12.13 \\
\hline
\end{tabular}

As can be noted from the table, the idealized deformation shape defined in Equations 15-20 does not necessarily give reliable prediction of the tube deformation by ship bow impact. This is because the contact areas of ship bow with the tube are irregular and not flat and therefore the dented section will not be plane. Nevertheless, the calculated results from Equations 15-20 show a reasonable accuracy when the deformation is relatively large, e.g., at least $30 \%$ of the diameter of the initial cross section. When the deformation is small, the prediction of these equations is not accurate, indicating the deformation shape and the contributions from denting and global bending are difficult to be idealized.

In regards to the energy assessment, the energy can be non-dimensionalized with respect to the static collapse load for bending $P_{u}$ given in Equation 12. According to Jones et al. (1992) the dimensionless energy is first defined, considering specimens with varying $D / t$ ratios, as:

$$
\begin{aligned}
& \lambda=\frac{E_{k}}{P_{u} t} \\
& \lambda=\frac{L E_{k}}{8 \sigma_{y} D^{2} t^{2}}
\end{aligned}
$$

where $P_{u} t$ represents the external work of the concentrated collapse load $P_{u}$ that produces a transverse displacement, $t$, right underneath the load application point. To account for the different material properties of tubes of similar geometry, Equations 21 and 22 are written in this study as:

$$
\Lambda=\frac{E_{k}}{P_{u} D}
$$




$$
\Lambda=\frac{L E_{k}}{4 \sigma_{u} D^{3} t}
$$

using $\sigma_{u}$ instead of $\sigma_{y}$ in the calculation of $P_{u}$. $\mathrm{t}$ was defined as the thickness before, use a different letter to avoid confusion, also define all the parameters in the equations

The maximum transverse displacements, in turn, can be written in a dimensionless form with respect to the wall thickness or the tube diameter. In Equations 21 to 24, however, the dimensionless energy is obtained from the initial kinetic energy. From the reported tests using a rigid striker, the remaining energy after the impact is divided between the strain energy of the tube and the kinetic energy due to rebound, being that the kinetic energy from the rebound represents a very small amount of the initial kinetic energy from the impact. This is consistent with the numerical simulations that at least $85 \%$ impact energy is converted to strain energy. The numerical results are compared with experimental results reported by Jones (1992) in Figure 17. The dimensionless energies are calculated based on the strain energy. Since in impacts with deformable strikers the strain energy of the tube can decrease significantly in terms of percentage of the total energy since the stricker will also absorb energy, it becomes plausible that the dimensionless energies take into account only the strain energy of the tube. In Figures 17 and 18 both dimensionless displacements and energies are considered. It is found that if the strain energy of the experimental tests with various $D / t$ ratios is assumed rather than the initial kinetic energy, the results will nearly follow a linear trend without significant dispersion for $\Lambda$ vs $\Delta / D$ and $\lambda$ vs $\Delta /$ t. For $\lambda$ vs $\Delta / D$ an approximate linear behavior can also be observed, and the numerical tests are better correlated by using a ratio of $60 \mathrm{for} D / t$. It shall be referred that these relationships take into account the total displacement of the membrane, regardless of the deformation modes. It should also be noted that the way the absorbed energies normalized normalized by a single static load at collapse might become inappropriate for the case of ship collision with a wider contact area since for similar penetration depth it will result in greater amounts of strain energy. The numerical results, divided into the different deformation modes are plotted separately in Figure 18. The main difference is observed for 'bending without denting' cases mainly for $\Lambda$ vs $\Delta / t$, which suggests that the dimensionless energies and the dimensionless displacements are better correlated if very long tubes with thick walls would not be considered. Jones (1992) also suggested, based on two sets of data, that geometrically similar scaling could be assumed for design purposes. For easier comparison, approximate values of $L / D$ are chosen with $D / t$ equal to 40 . The scale factors, $\chi$, for diameter and thickness havevery close range of values of 0.900-1.922 for $t$ and 1.001-2.135 for $D$. Even though it is not totally clear due to a gap and possibly some lack of sufficient data, it appears that the results plotted in Figure 19 seem to agree with the experimental tests as a linear trend could be projected over the chart. Therefore, the principles of geometrically similar scaling can be assumed to be appropriate also for impacts using deformable strikers. 

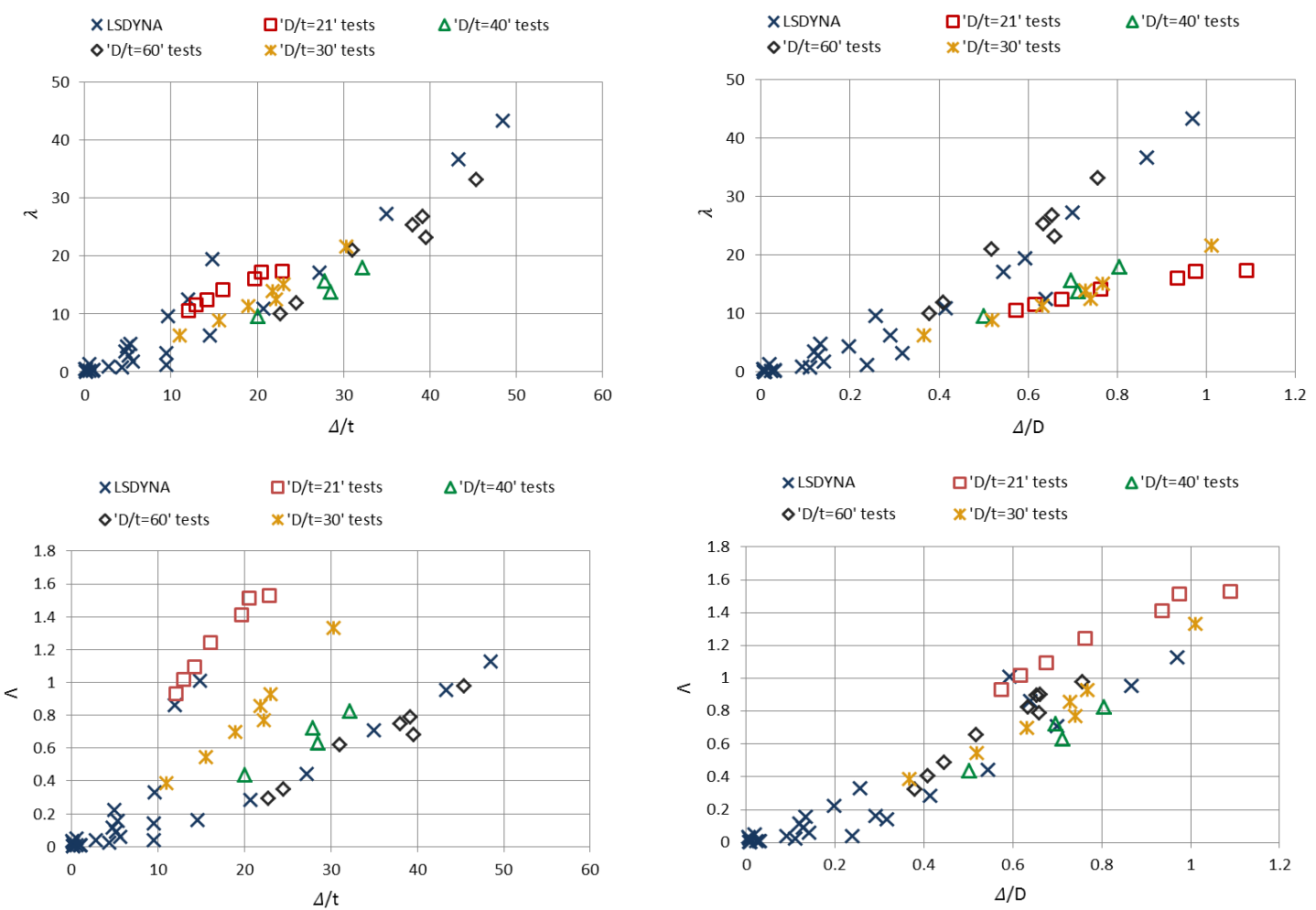

Figure 17. Comparison of maximum dimensionless strain energy versus maximum non-dimensional displacement for fixed tubes for numerical and experimental tests
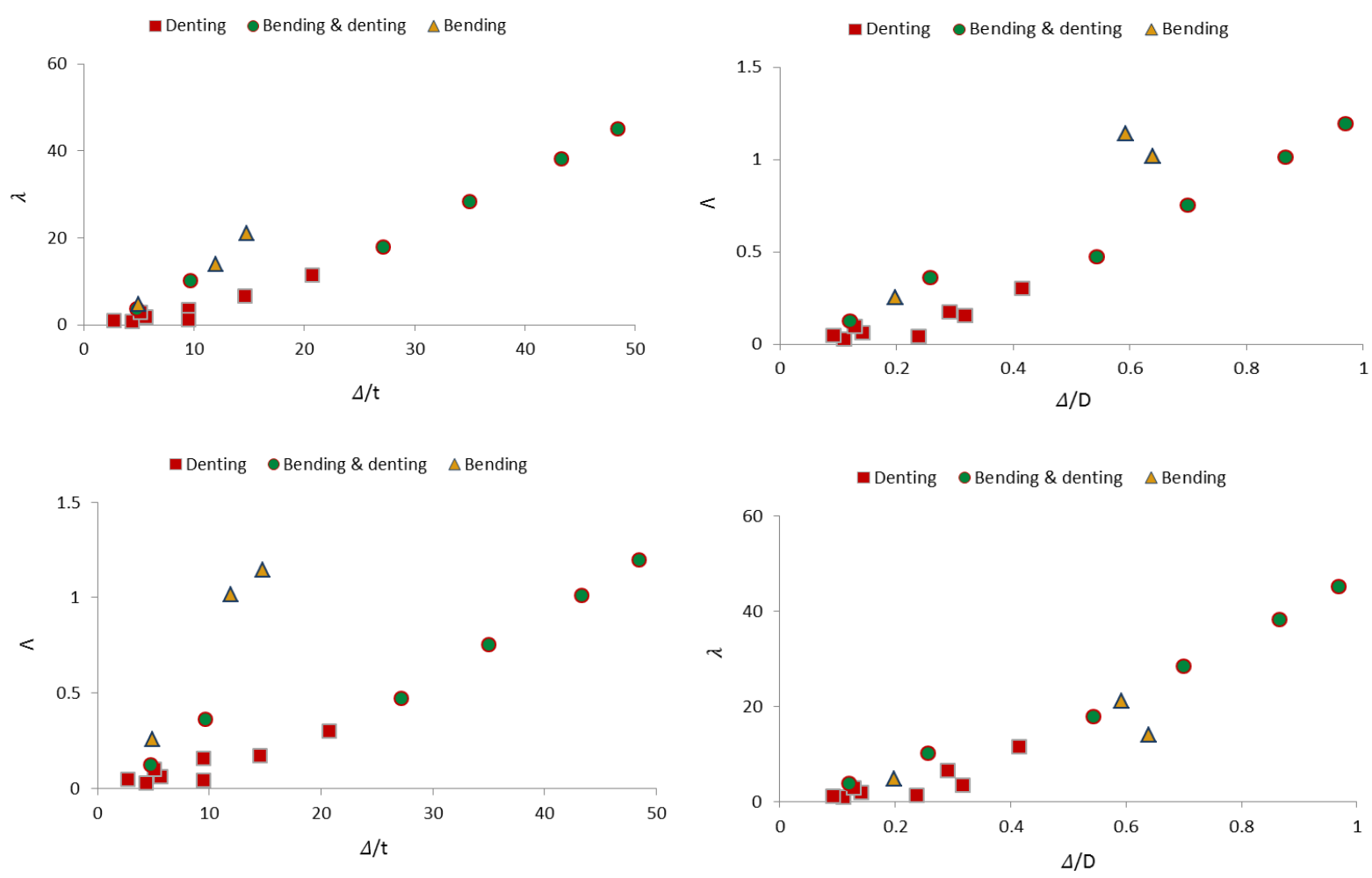

Figure 18. Maximum dimensionless strain energy versus maximum non-dimensional displacement for fixed tubes considering different deformation modes 


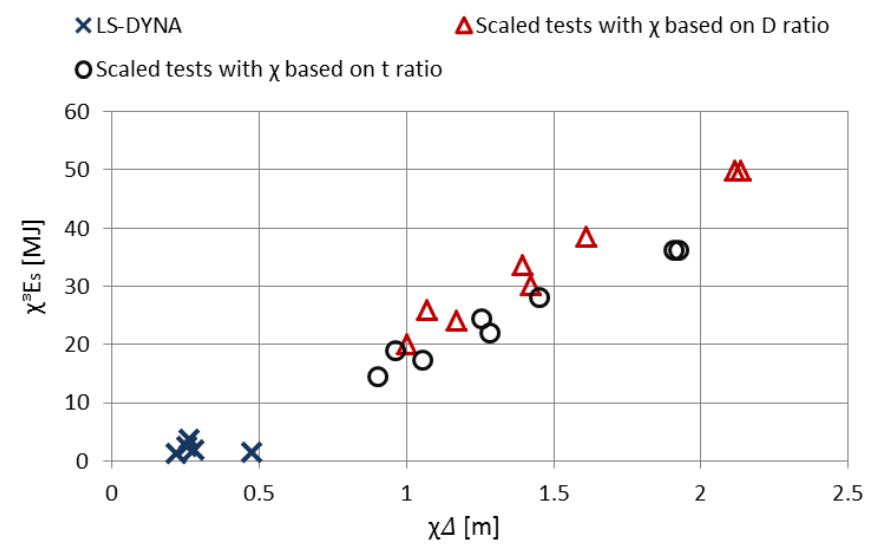

Figure 19. Scaled maximum membrane displacement $(\Delta)$ versus scaled strain energy of tubes $\left(\mathrm{E}_{\mathrm{s}}\right)$. Scaled tests (Jones, 1992)

Figure 20 shows the amount of kinetic energy absorbed by the leg with respect to the plastic moment of the tube wall and the tube slenderness. It is obvious that bending response absorbs more energy than local denting even for shorter members with thinner walls, for which local denting also contributes to significant amounts of energy absorption. As expected, the maximum energy absorption results from the combination of the two deformation modes when the tube is slender with large bending deformation and the wall is thin with considerable denting deformation (see also Table 6).

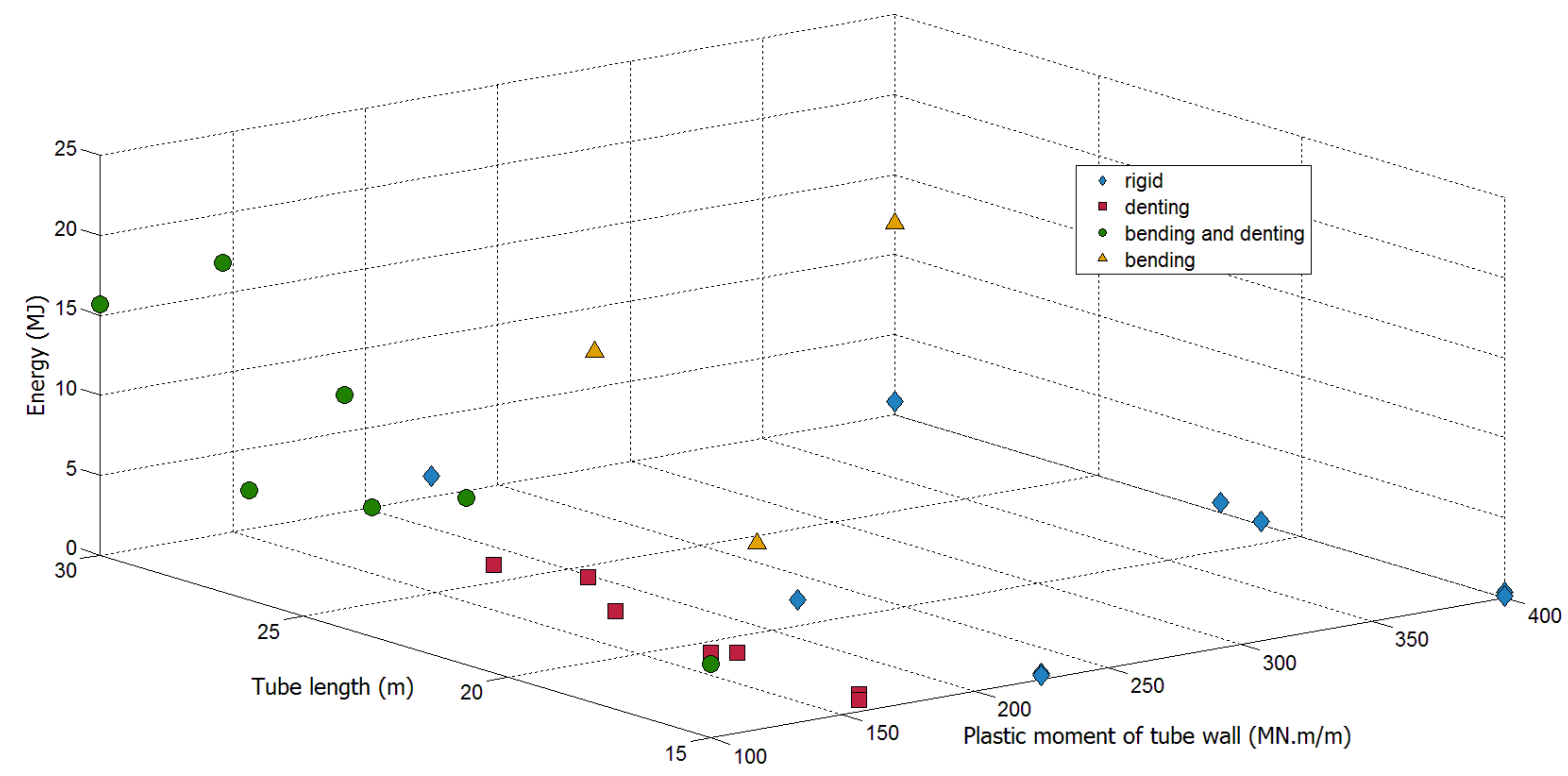

Figure 20. Geometry vs. absorbed energy of tubes

The energy absorption by plastic deformation of the platform steel member therefore depends on both plastic hinge formations due to bending and plastic wall deformation owing to local denting. For structure integrity, it is important that denting should be minimized. According to the API (2000), the maximum value that the ratio $D / t$ shall assume in the design in order to maintain the full capacity of the cross section through plastic deformation is $9000 / \sigma_{y}$. It can be seen from Figure 16 that the tubes with wall thickness of $60 \mathrm{~mm}$ or higher will not experience any significant local denting at any point 
along their length when crashed by the ship of section 3.1. Although the API data are for broadside collisions, the analyses for bow collision with appropriate parameters seem to agree with the same conditions.

The 8.5 MN of a concentrated load obtained by Amdahl and Johansen (2001), as the maximum admissible concentrated load to prevent a tube wall of $80 \mathrm{~mm}$ thick from denting, reveals to be much larger than those obtained in the current study. Table 7 gives the maximum forces to prevent local denting obtained in this study. It should be noted that these results are obtained with the two types of contact areas illustrated in Table 9 and the contact force assumed to be uniformly distributed in the contact area, and the tube diameter is $2 \mathrm{~m}$ and wall thickness of at least $60 \mathrm{~mm}$.

Table 7. Local collision forces evenly distributed over a regular area

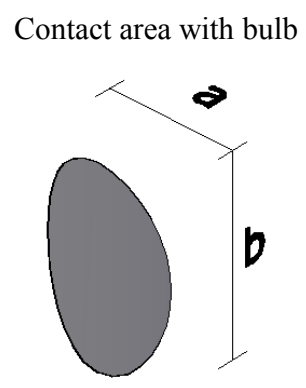

Contact area with superstructure

\begin{tabular}{|c|c|c|c|c|}
\hline \multirow{2}{*}{$\begin{array}{c}\text { Contact } \\
\text { area }\end{array}$} & $\mathrm{a}(\mathrm{m})$ & 0.6 & 0.8 & 1.2 \\
\cline { 2 - 5 } & $\mathrm{b}(\mathrm{m})$ & 0.5 & 1.3 & 2.3 \\
\hline \multicolumn{2}{|c|}{ Force $(\mathrm{MN})$} & 1.94 & 4.28 & 5.24 \\
\hline \multirow{2}{*}{$\begin{array}{c}\text { Contact } \\
\text { area }\end{array}$} & $\mathrm{c}(\mathrm{m})$ & 0.3 & 0.7 & 1.2 \\
\cline { 2 - 5 } & $\mathrm{d}(\mathrm{m})$ & 0.6 & 0.8 & 1.2 \\
\hline \multicolumn{2}{|c|}{ Force $(\mathrm{MN})$} & 0.85 & 2.04 & 3.70 \\
\hline
\end{tabular}

For the 'only denting' cases, the tube absorbed energy is listed in Table 8 . As can be noticed, denting only absorbs a small amount of the total energy. Most impact energy is absorbed by the global bending deformation of the tubular member and ship structure deformation as will be discussed in more detail later.

Table 8. Energy absorption for impacts on legs (only dented)

\begin{tabular}{|c|c|c|}
\hline \multirow{2}{*}{ Test } & \multicolumn{2}{|c|}{ Energy (MJ) } \\
\cline { 2 - 3 } & Platform dented member & $\begin{array}{c}\text { Total Deformation } \\
\text { Energy }\end{array}$ \\
\hline D2t40L15 & 5.37 & 53.91 \\
\hline D2t50L15 & 1.09 & 53.84 \\
\hline D2t50L21 & 1.71 & 54.04 \\
\hline D1.5t50L15 & 0.72 & 53.88 \\
\hline D2t40L18 & 7.80 & 55.70 \\
\hline D1.5t50L18.5 & 1.99 & 55.61 \\
\hline D2t50L18 & 1.39 & 55.56 \\
\hline D2t50L24 & 2.32 & 55.73 \\
\hline
\end{tabular}

Despite the same total impact energy from ship considered in all the cases, the absorbed energy owing to plastic deformation of platform member and ship differ slightly, indicating different amounts of 
kinetic energy of rebound that can take place after the impact. However, the energy absorbed by the platform member denting deformation differs significantly, indicating very different plastic deformations for different structural conditions. The maximum absorbed energy of 7.80 MJ registered on dented tubes corresponds to a larger damaged area, not necessarily the deepest ship penetration. The differences are noticeable when the wall thickness changes. It should be noted that bending of the steel members will absorb additional amounts of the impact energy, which are not included in Table 8 . In fact, the clamped tubes undergoing bending with or without dent of the cross section can absorb great amounts of impact energy due to the flexural deflection, depending on the tube length, usually larger than that due to the membrane displacement (denting deformation) as will be discussed below.

Considering the flexural response, it is found that the maximum displacement of the tube elements on the compressive side of the tube in direct contact with the ship bulb occurs slightly below the midlength of the tube element. The non-dimensional displacement, representing the horizontal displacement of the tube membranes regardless of the governing response, when related to the strain energy, increases linearly. Figure 21 confirms, from all the numerical simulations considering fixedends tubes, that the energy absorption is proportional to the total deformation of the tubular member irrespective if it is local denting or global bending deformation.

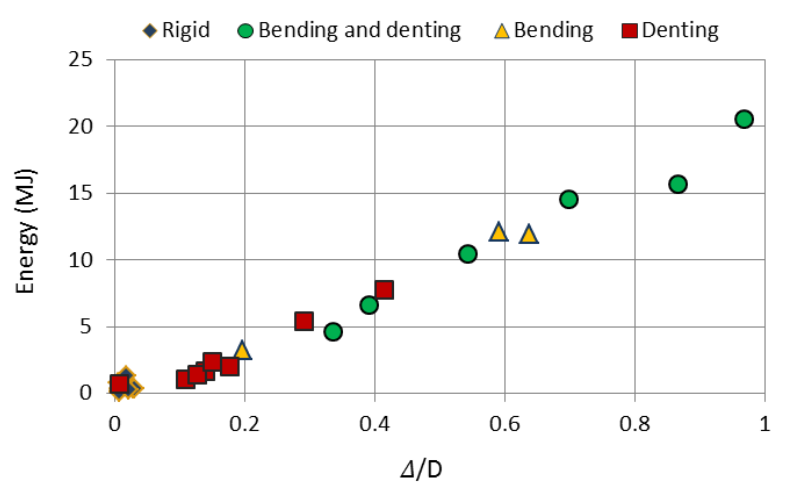

Figure 21. Energy vs. non-dimensional displacement of tube membrane ( $\Delta$ - total displacement of membrane; D - diameter of the tube)

\subsection{Bow strength}

Within a design scenario where the strain energy is dissipated over the two colliding bodies, it is of interest to determine the amount of energy dissipation by each body with varying parameters. As said earlier, the bow model geometry defined in 3.1 is a replica of the model used by Amdahl and Johansen (2001) to define the bow deformation behavior in high energy collisions. The vessels analyzed by Pedersen (1992) have the plate thickness of the 2000DWT ranged from 8.5 to $18.0 \mathrm{~mm}$, meaning a higher plate thickness average than the $11.0 \mathrm{~mm}$ assumed in this study. To study the influences of bow plate thickness on ship-platform interaction, similar simulations as those presented above are repeated with the shell thickness of the bow model increased to $14 \mathrm{~mm}$. The peak of the contact forces are obtained as $27.72 \mathrm{MN}$ and $20.32 \mathrm{MN}$ from the bow crushing against a rigid wall and a rigid cylinder of $2 \mathrm{~m}$ diameter, respectively, higher than the cases from the previous simulation of $17 \mathrm{MN}$ peak force when the ship plate thickness is $11 \mathrm{~mm}$. Figure 22 shows the energy absorption with respect to the bow crushing distance. As expected, a thicker bow plate corresponds to less crushing distance at the same amount of energy absorption. 


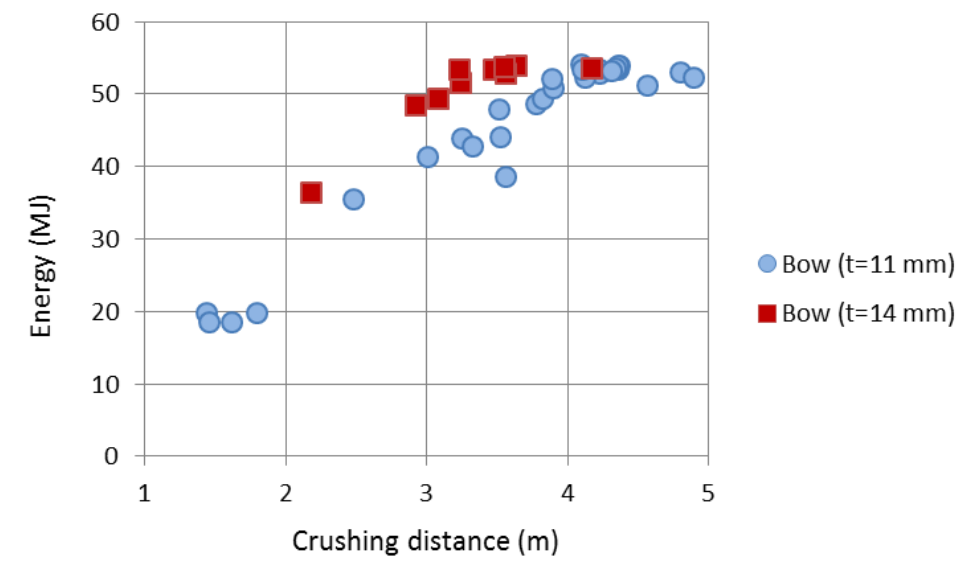

Figure 22. Energy vs. bow crushing distance

To examine the influences of the bow and tubular structure interaction on impact forces, numerical simulations are carried out with bow plate thickness of $11 \mathrm{~mm}$ and $14 \mathrm{~mm}$, and tubes of different length, diameter and wall thickness. The simulated impact force time histories are shown in Figure 23. As shown, in general increasing the stiffness of bow structure and tube structure leads to a larger impact force but shorter force duration. The detailed simulation results, which are not shown here, also demonstrate that the $60 \mathrm{~mm}$ thick wall of the tube experiences only small local denting deformation under the collision of ship with bow plate thickness of $14 \mathrm{~mm}$ and $X / D$ not greater than $8 \%$, as compared to almost no deformation when the bow plate thickness is $11 \mathrm{~mm}$ as discussed in 5.1 above. When the tube wall is $80 \mathrm{~mm}$ thick, no obvious local denting deformation is generated even the bow plate is $14 \mathrm{~mm}$ thick. These results indicate that the relatively weaker structure, either bow or tube, will experience larger plastic deformation and absorb more energy during the collision.

The reduction of the impact duration of about $0.25-0.5$ seconds with the increase of the bow strength (plate thickness here) is observed in Figure 23. The higher difference occurs in the cases of the tubes behaving rigidly and undergoing bending deformation, implying the tube deformation and particularly bending deformation prolongs the ship collision process. The impact duration predicted as 0.49 seconds by Equations 5 and 6 in a strength design scenario is far shorter than what is obtained in the present calculations because those equations were derived without considering interactions between ship and tube structures during impacting. By assuming the maximum penetration of a rigid obstacle with unlimited width, the duration would ascend to 0.84 seconds in Equations 5 and 6, still less than the 1.26 seconds obtained when colliding of the stronger bow against a rigid wall, i.e. the same impacting scenario considered in Pedersen's (1992). These observations indicate those equations significantly underestimate the impact loading duration. 

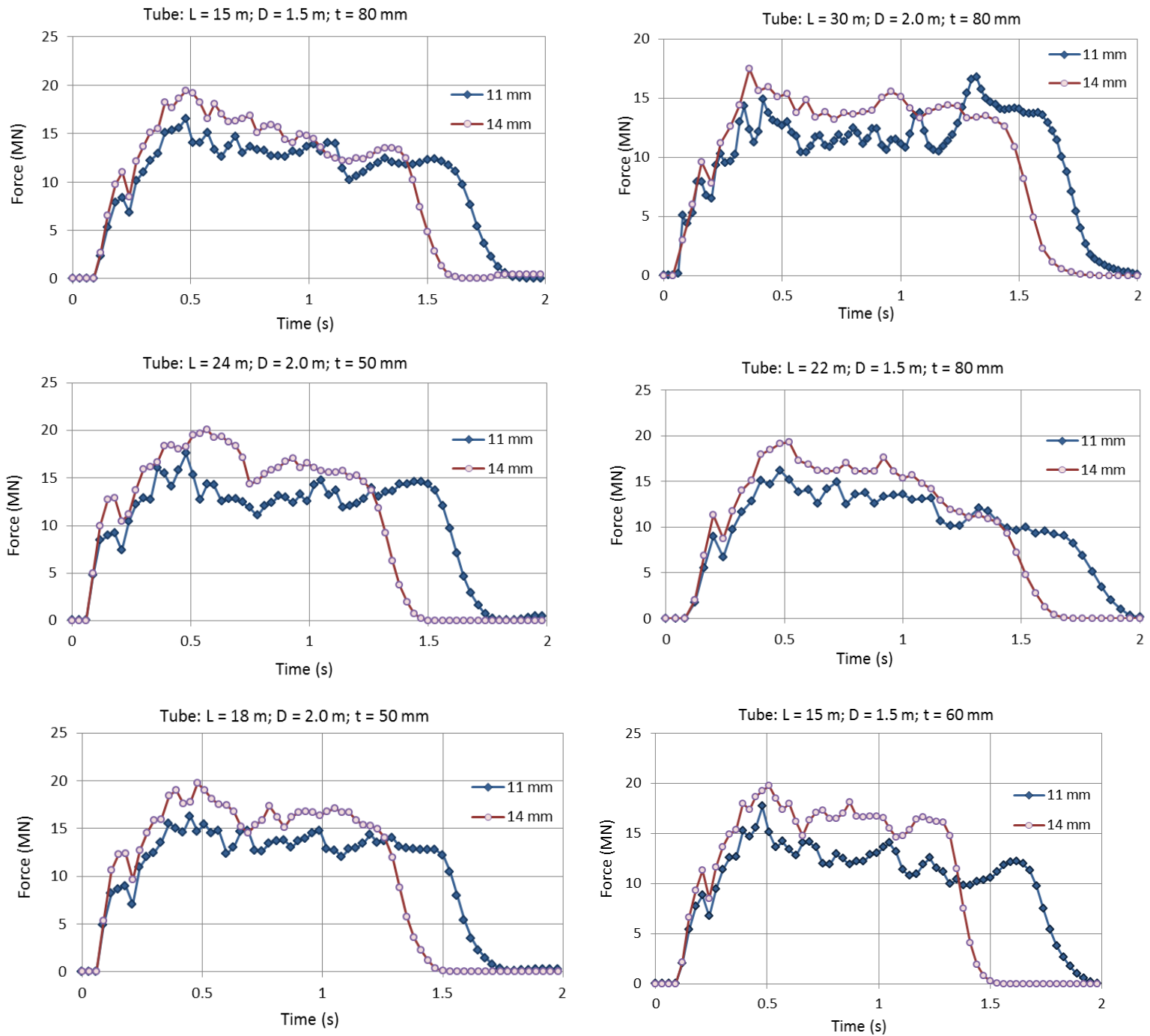

Figure 23. Force-time history of contact forces from ship bows of different strength

\subsection{Boundary conditions}

In the above simulations, the tubes are assumed as clamped on the both ends. Such assumption, however, does not necessarily represent the true boundary conditions of tubular members in a steel offshore platform. Since the boundary conditions of the tubular member affect its bending deformation and ability to resist impact loads, for example the longitudinal membrane forces and plastic hinges are not developed at the ends of a pinned tube, and the value of the plastic limit load defined in Equation 12 is reduced to half when the ends switch from fixed to pinned, the influences of boundary conditions are investigated in this section.

To model the free rotation condition at the tube ends, an extra node at the center of each tube end cross section is defined. The translational degrees of freedom of this additional node are restrained but it can rotate freely. All the nodes at the tube end cross sections are rigidly connected to this center node. Thereby the tube end can rotate with respect to the center node. It should be noted that for a real tubular member in a platform structure, its boundary conditions are neither fully fixed nor pinned. The two boundary conditions considered in the present study represent the two idealized cases. The true behaviors are in between these two extreme boundary conditions 
Six cases have been considered for the different deformation scenarios in 5.1. The comparison between the same cases for the pinned and fixed ends is given in Table 9. As can be noticed, although the ultimate plastic load of a beam with pinned ends is reduced to half, this does not mean that the total impact loads for which the contact occurs until the collapse of the jacket leg would be reduced by the same amount. The contact force is affected by the deformations of the ship bow as well. The peak values of the contact forces obtained for the cases under consideration are actually very close for the two tube boundary conditions, as can be noted in Table 9 .

Table 9. Data for hit tubes with different boundary conditions

\begin{tabular}{|c|c|c|c|c|c|}
\hline Tube & Ends & $\begin{array}{l}\text { Impact duration } \\
\text { (s) }\end{array}$ & $\begin{array}{c}\text { Energy } \\
\text { absorbed (MJ) }\end{array}$ & $\begin{array}{l}\text { Estimated } P_{u} \\
\text { from Eq. } 12 \\
(\mathrm{MN})\end{array}$ & $\begin{array}{c}\text { Maximum } \\
\text { contact force } \\
(\mathrm{MN})\end{array}$ \\
\hline \multirow{2}{*}{ D1.5t40L18.5 } & fixed & $0.92 *$ & $9.6^{*}$ & 9.7 & $15.1^{*}$ \\
\hline & pinned & $1.01 *$ & $15.4^{*}$ & 4.9 & $16.3^{*}$ \\
\hline \multirow{2}{*}{ D1.5t50L22 } & fixed & $1.02 *$ & $1.0 *$ & 10.2 & $14.8^{*}$ \\
\hline & pinned & $0.94 *$ & $12.1^{*}$ & 5.1 & $16.0^{*}$ \\
\hline \multirow{2}{*}{ D1.5t80L30 } & fixed & 1.90 & 12.0 & 12.0 & 16.3 \\
\hline & pinned & 2.05 & 11.3 & 6.0 & 16.6 \\
\hline \multirow{2}{*}{ D2t50L21 } & fixed & 1.90 & 1.7 & 19.0 & 16.4 \\
\hline & pinned & 1.90 & 12.3 & 9.5 & 15.4 \\
\hline \multirow{2}{*}{ D2t40L27 } & fixed & 1.78 & 20.6 & 11.9 & 16.2 \\
\hline & pinned & 1.82 & 23.2 & 5.9 & 16.3 \\
\hline \multirow{2}{*}{ D2t60L30 } & fixed & 1.90 & 1.3 & 16.0 & 17.2 \\
\hline & pinned & 2.15 & 13.6 & 8.0 & 13.6 \\
\hline
\end{tabular}

*Tube collapse due to failure of steel

The duration of the impact is naturally shorter for the clamped tubes and the occurrence of the peak of the contact force in general takes place earlier as compared to those of the pinned tube because the different structural stiffness corresponding to the two boundary conditions. Simulation results, which are not shown here, also indicate different deformation modes when the tubes have different boundary conditions. For example, as presented above, when the ship with $11 \mathrm{~mm}$ bow plate thickness collides with the fixed ends tubular member with tube wall thickness $60 \mathrm{~mm}$, it induces almost no local denting deformation in the tube wall. However, very small local denting deformation that occurs due to the absence of axial membrane forces can be observed under the same colliding condition when the tubular member has pinned boundaries and undergoes global deflections. The percentages of energy absorption also vary with the different deformation modes. Nonetheless, most of the energy is still absorbed by the tube global bending deformation, the same as that discussed above for the case with fixed ends tube structure. Because the pinned boundary makes the tube structure more flexible than the fixed boundary, the impact duration increases but the plateau of the maximum average contact force reduces (Figure 24). The failure mode of the tubes i.e., the cases in which the steel strain reaches the predefined value of 0.15 in this study, leading to erosion of the finite elements and consequent rupture, is also different. For the tubes with pinned ends, the rupture occurs at mid length of the member where plastic hinge is formed and the contact stress is greater, whereas for clamped members the rupture occurs at the lower end of the member. 


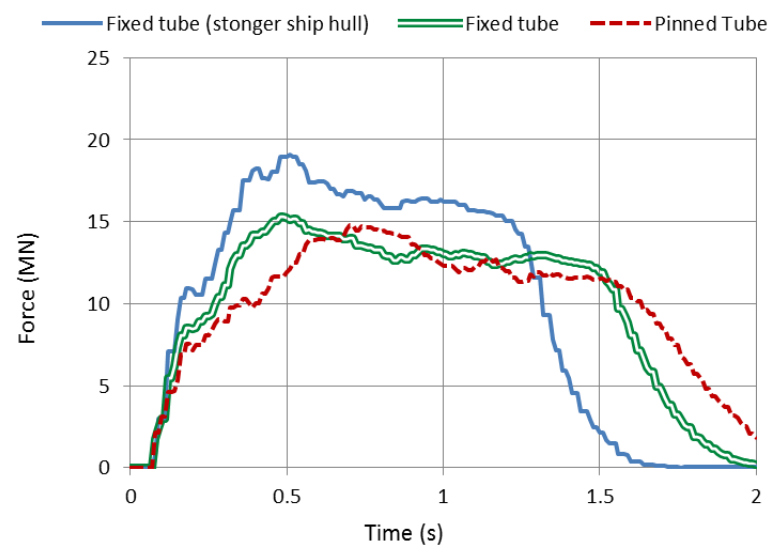

Figure 24. Average contact loads

Although no general conclusion can be drawn for the amplitude of impact force with respect to the tube boundary conditions, the boundary condition has consistent influences on absorbed energy of the tube. In Figure 25 the results corresponding to the cases presented in Table 9 are plotted and compared, similar to the discussions presented in section 5.1. The cases with failure occurrence are also included. As shown, it is possible to establish a connection between the dimensionless absorbed energy and displacement. It should be noted that the values of the non-dimensional energy for pinned members are obtained from Equations 21 to 24 by considering $P_{u}$ as half of the expression given in Equation 12 for fixed-ends members.

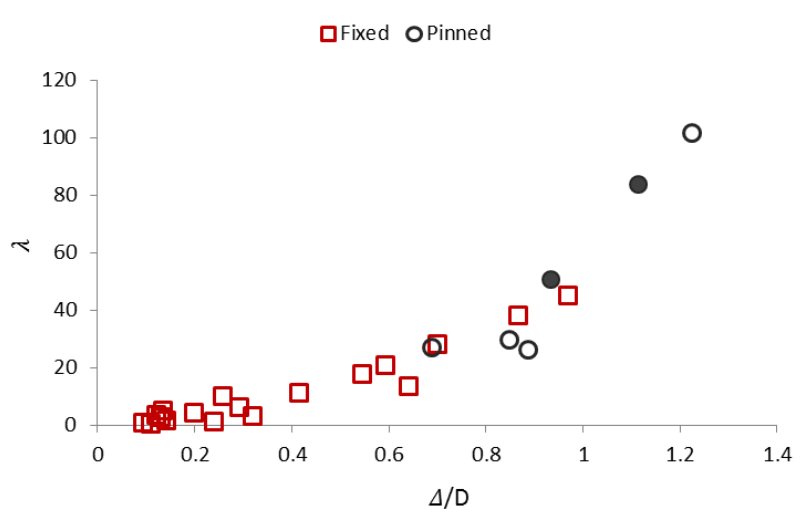

Figure 25. Maximum dimensionless strain energy versus maximum non-dimensional displacement for tubes considering different boundary conditions $(\bullet$ failed $)$

\subsection{Axial preloading}

Since the offshore platforms are carrying their design loads during the ship impact, it is of significance to analyze how the tube response is affected when subjected to axial stress. The combination between the axial prestress and the lateral impact load may increase the chance of failure due to buckling of the tubular member and consequently the failure of the whole platform. To examine the preload effects on the legs laterally impacted by the bow, some of the previous cases are analyzed again with the axial pre-compression added. To study the coupled effects of boundary conditions and axial loading, besides the geometric properties of the tubes, the end restraints are also alternated between fixed and pinned conditions. 
The numerical calculations involving axial preloading consist of two steps. The "dynamic relaxation" is applied at the beginning with the application of the design loads necessary for the desired axial stress to be achieved prior to the second-step impact analysis. The levels of preloading that have been introduced in this study correspond to the $50 \%$ of the allowable axial compressive stress, $F_{a}$, obtained from the API code.

The tube parameters for the analysis of the axial preloading effects are given in Table 10 .

Table 10. Parameters of the preloaded tubes analyzed in this study

\begin{tabular}{|c|c|c|c|c|c|}
\hline Case & Tube & Ends & $\begin{array}{c}50 \% \mathrm{~F}_{\mathrm{a}} \\
(\mathrm{MPa})\end{array}$ & $\begin{array}{c}P_{u} \\
(\mathrm{MN})\end{array}$ & $\begin{array}{c}\text { Maximum } \\
\text { contact force } \\
\text { recorded (MN) }\end{array}$ \\
\hline 1 & D1.5t60L26 & Fixed & 63.3 & 10.4 & $9.3^{*}$ \\
\hline 2 & D1.5t80L30 & Pinned & 60.6 & 6.0 & $10.1^{*}$ \\
\hline 3 & D2t50L22 & Fixed & 68.7 & 18.1 & $9.8^{*}$ \\
\hline 4 & D2t60L30 & Fixed & 65.5 & 16.0 & $7.9^{*}$ \\
\hline 5 & D2t80L30 & Fixed & 65.4 & 21.3 & 16.5 \\
\hline 6 & D2t80L30 & Pinned & 65.4 & 10.6 & $12.5^{*}$ \\
\hline 7 & D2t50L15 & Fixed & 71.1 & 26.6 & 16.1 \\
\hline 8 & D1.5t80L15 & Pinned & 69.2 & 12.0 & 16.6 \\
\hline 9 & D2t60L15 & Pinned & 71.1 & 16.0 & 15.7 \\
\hline
\end{tabular}

*Tube collapse due to failure of steel $\left(P_{u}\right.$ calculated according to Equation 12$)$

As the $D / t$ ratio for the selected tubes is greater than 60 , it is not expected according to API code as well as the FE simulation results presented above that significant local buckling would take place. Therefore, only global buckling can lead to the member failure.

A previous study demonstrated that the application of axial preloading affects the force versus tube deformation, namely local denting, relationships (Khedmati and Nazari, 2012). Both the maximum load capacity of the tubes and tube maximum deformation can diminish substantially with the increase of preloading. For the case with a preloading of $50 \%$ of the maximum allowable stress according to the API, the maximum impact load that is reached prior to the tube collapse drops down to nearly half for the same tube with no pre-compression applied. Likewise, the lateral displacement of the tube membrane in contact with the striker also reduces substantially. This observation is, however, different from those obtained in the present study. The results presented in Table 10 indicate that despite axial preloading reduces the lateral load-carrying capacity, it has little influence on the peak impact loads on the tube from ship impact. This can be attributed to the short impact duration. In other words, the peak of impact load is reached before the tube experiences significant deformation and failure. Therefore the axial preloading has little effect. The conclusion made in Khedmati and Nazari (2012) was based on static simulation that neglects the dynamic effect. The results obtained in the present study demonstrate that dynamic effect may have a profound influence on the ship-tube structure interaction (Figure 26). Those based on static analysis do not necessarily provide reliable predictions. 

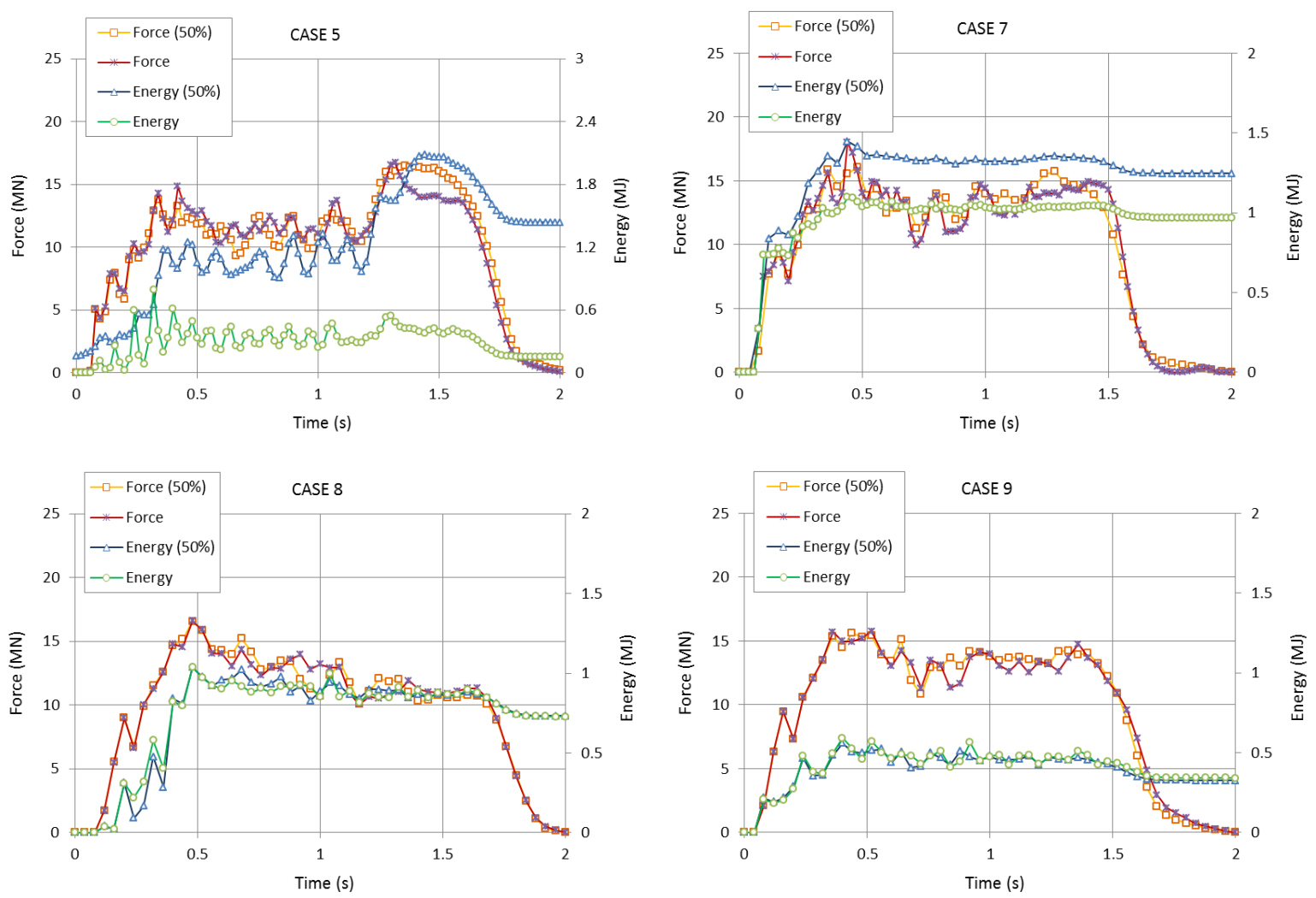

Figure 26. Behavior of tubes under prestress

\subsection{Dynamic parameters}

The majority of the available methods that are employed to assess the platform-ship collisions make use of quasi-static solutions due to the relatively low velocity of the ships during the impact. This seems acceptable as the local inertia effects of the structures are very low. However, the ship and tubular structure interaction during impact is a dynamic process. The material strain rate effects can be noticeable in some regions reaching plasticity even for relatively low velocity impact. The dynamic flow stress becomes larger than the static yield stress. This might lead to higher peaks of the contact forces and shorter duration of the impact. In this section, the dynamic effects, in particular the strain rate effect on ship-tube interaction are investigated.

To model the material strain rate effect, the coefficients $C$ and $P$ from Equation 13 are usually set as $40.4 \mathrm{~s}^{-1}$ and 5, respectively (Yang and Caldwell, 1988). These values are suitable for mild steel under uniaxial tensions with small strains. Paik (2010) stated that those coefficients result in a very small value for the fracture strain. Several authors have conducted many research works to model the strain rate effects and suggested different parameters. Abramowicz and Jones (1984) suggested the values of $C=6844 \mathrm{~s}^{-1}$ and $P=3.91$ to be used for dynamic crushing of mild steel square tubes, whereas Yang and Caldwell (1988) defined $C=500 \mathrm{~s}^{-1}$ and $P=4$ to assess the energy absorption of ship bow structures. Values in the range of 7000-10000 s-1 and 2 to 4 respectively for $C$ and $P$ were also recommended to avoid too small values of the fracture strain (Paik and Thayamballi, 2003 and Paik, 2010). High strength steels might assume values of $3200 \mathrm{~s}^{-1}$ and 5 for $\mathrm{C}$ and $\mathrm{P}$ (Paik and Chung, 1999).

These significant differences in those constants recommended by different researchers are because Equation 13 was derived based on uniaxial tensile tests with constant strain rate. These values are 
likely to be different when it comes to bending of beams or even local denting. By integrating Equation 13 over the cross section and deriving the dynamic bending moment, Aspden and Campbell (1966) could estimate the curvature rate of the structure. Nevertheless, most of the researchers have chosen to apply Equation 13 to directly estimate the strain rate. In this study Equation 13 with constants $C=40.4 \mathrm{~s}^{-1}$ and $P=5$ is still employed to model the strain rate effects as they are most commonly adopted by different researchers. Figure 27 compares the force-deformation relationships of a bow crushed by a rigid column of $2 \mathrm{~m}$ diameter for impact speeds of $3 \mathrm{~ms}^{-1}$ and $6 \mathrm{~ms}^{-1}$ with and without the influence of the strain rate effects $\left(C=40.4 \mathrm{~s}^{-1}\right.$ and $\left.P=5\right)$. As shown, neglecting the strain rate effects gives very different predictions of the impact force time history, especially when the ship velocity is relatively high. These results demonstrate the importance of considering the strain rate effect in numerical simulations.

To further study the strain rate effects, some numerical simulations are conducted here for collision with two deformable structures with different strain rate constants as listed in Table 11. The simulation results are shown in Figure 28.
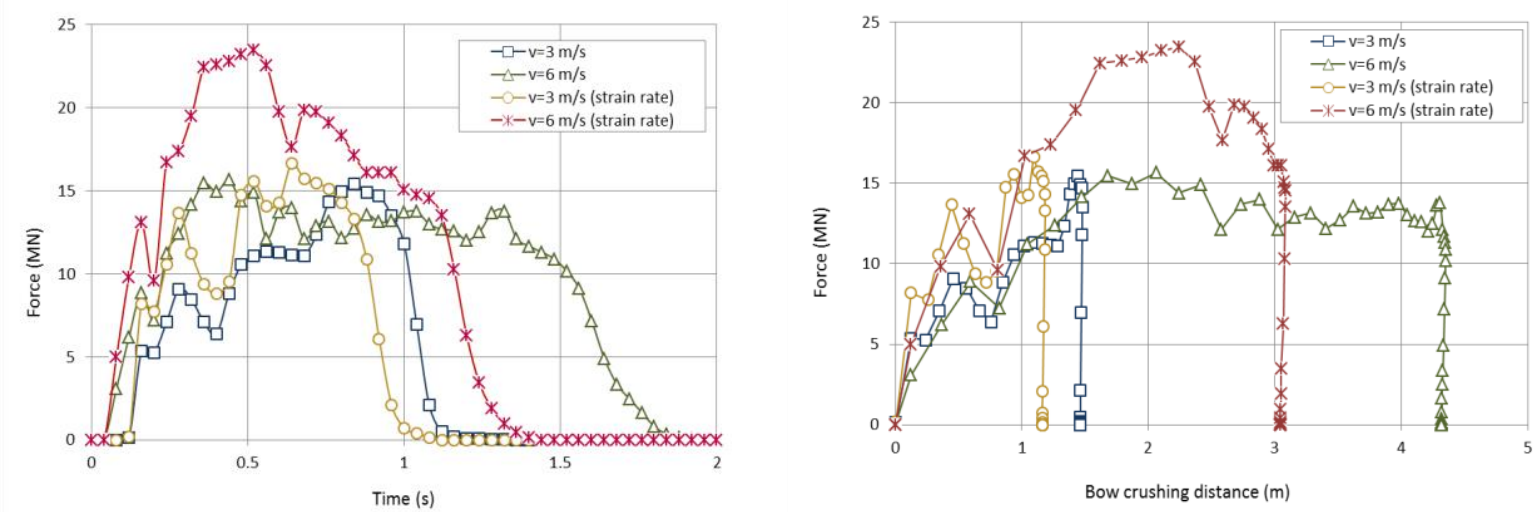

Figure 27. Impact velocity analysis with and without strain rate effects

Table 11. Parameters for strain rate numerical tests

\begin{tabular}{|c|c|c|c|c|c|}
\hline \multirow{3}{*}{ Case } & \multicolumn{4}{|c|}{ Strain rate values } & \multirow{3}{*}{$\begin{array}{l}\text { Impact velocity } \\
\left(\mathrm{ms}^{-1}\right)\end{array}$} \\
\hline & \multicolumn{2}{|c|}{ Tube } & \multicolumn{2}{|c|}{ Bow } & \\
\hline & $\mathrm{C}\left(\mathrm{s}^{-1}\right)$ & $\mathrm{P}$ & $C\left(s^{-1}\right)$ & $\mathrm{P}$ & \\
\hline A & 40.4 & 5 & 40.4 & 5 & 6 \\
\hline B & 40.4 & 5 & 6844 & 3.9 & 6 \\
\hline $\mathrm{C}$ & 40.4 & 5 & 500 & 4 & 6 \\
\hline
\end{tabular}


Tube: $L=30 ; \mathrm{D}=1.5 \mathrm{~m} ; \mathrm{t}=80 \mathrm{~mm}$; pinned
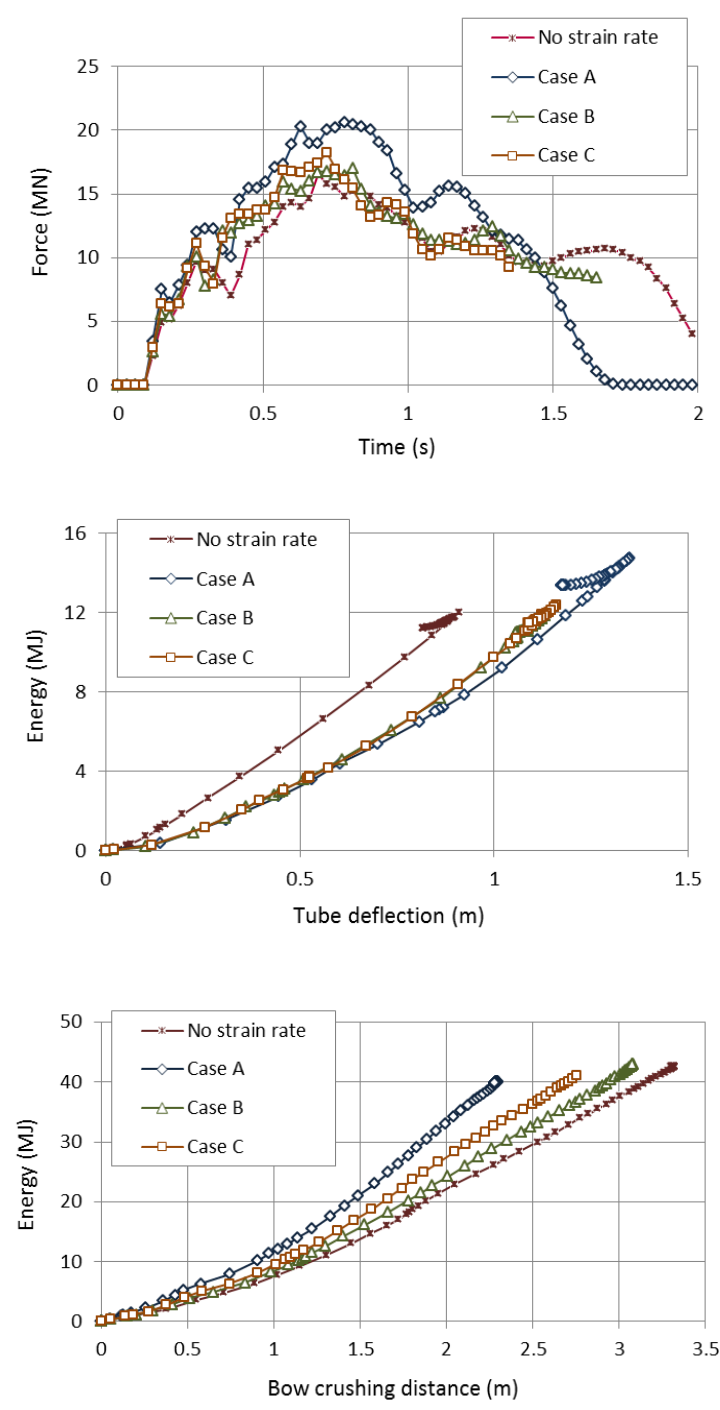

Tube: $\mathrm{L}=30 ; \mathrm{D}=2.0 \mathrm{~m}$; $\mathrm{t}=50 \mathrm{~mm}$; clamped
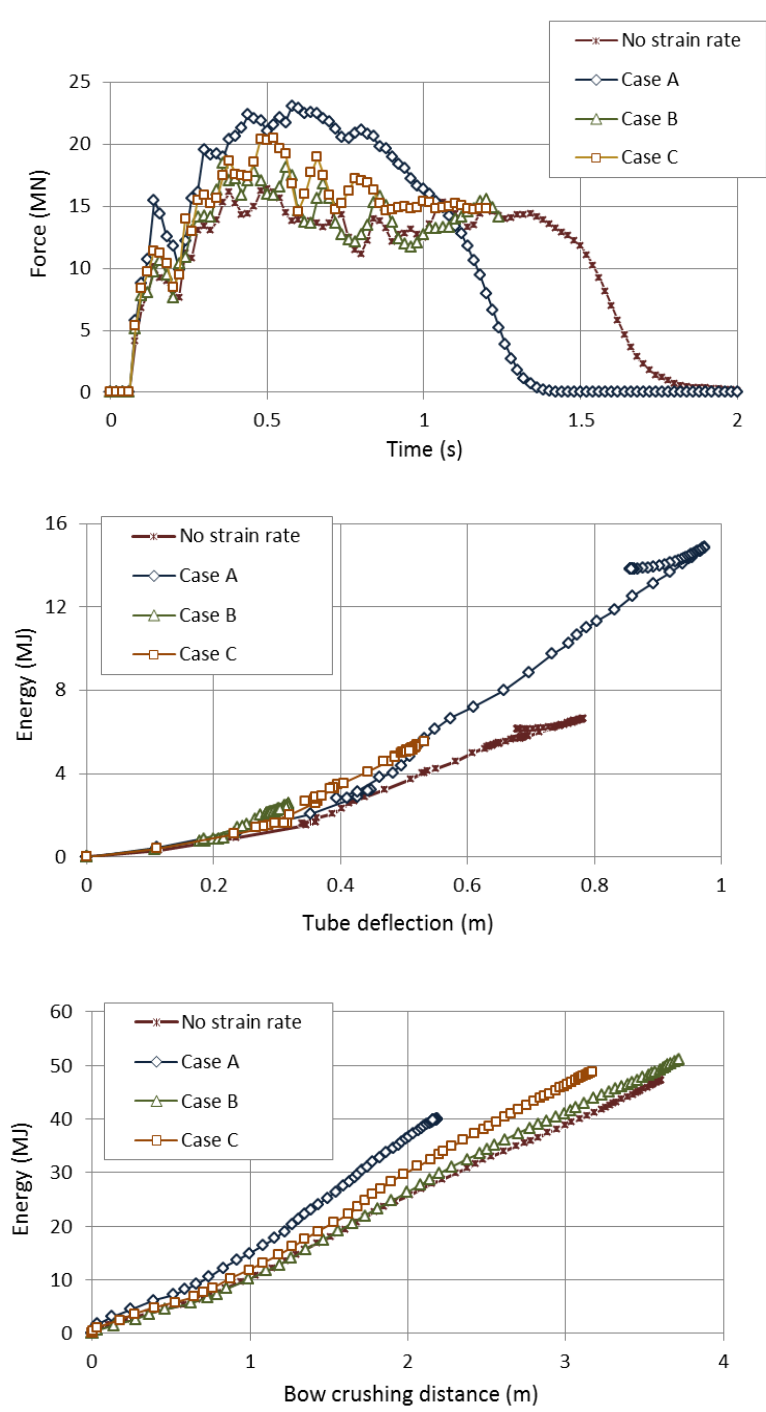

Figure 28. Influence of strain rate effect model on simulation results

By comparing the results in Figures 27 and 28, it can be concluded that it is important to correctly model the strain rate effect in numerical analysis. Using different strain rate effect models may result in different predictions. For example, the use of a low value for $C$ results in different predictions from the other cases, mainly resulting in higher peaks of the contact force and shorter duration of the impact. Further study is deemed necessary to define the appropriate strain rate effect of ship and tube materials.

\section{Discussion and recommendations}

The current design practise of offshore platforms against accidental loads such as ship impacts normally considers the events of high probability of occurrence. The deformation caused by ship impacts on jacket legs usually considered is therefore due to broadside collisions that can occur during berthing at very low speeds. For this reason no deformation on the ship structure is considered. When assessing the global deformation of tubular beams the contact area is usually assumed very small and takes place only at one single point. 
In reality, the collision risk with offshore platforms might not be limited to broadside collisions. Some studies of bow collision with offshore platform structures have also been reported in the literature. The previous studies with respect to bow collisions with jacket legs at relatively high speed, however, usually neglect the interactions of bow and platform structures (Amdahl and Johansen, 2001). The platform structure is commonly assumed to be rigid and impact force is related with the bow crushing distance. Consequently, the expressions previously adopted to predict the exerted force from the ship impact might not be accurate. As presented above, the current numerical simulations that consider the ship and platform structure interaction have demonstrated the possible significant dissipation of the strain energy over the two bodies in contact, and the geometry of the tube wall deformation depends also on the bow shape and stiffness, as well as the tube geometry and stiffness, and all these parameters affect the ship-tube interaction and the impact force.

This section discusses the limitations of the current practice in predicting the impact force, deformation and energy absorption associated with ship bow impacting on tubular jacket legs, and suggests possible improvements that consider the ship and platform structure interaction for better design and protection of offshore platform structures against ship impacts.

\subsection{Bow response}

The generic bow structure considered in the study has been used by other researchers and represents the general bow structure designs in a cargo or oil tank. Therefore the numerical results presented in this study give a more precise understanding of what to expect from a jacket leg, and to some extent from a jacket platform, when subjected to collisions involving ships of similar sizes and initial kinetic energies than those in the current design practise.

The current FE analysis results show the importance of the ship-platform interaction. The design curves currently adopted in the $\mathrm{DnV}$ code were obtained with the assumption of ship collision on a rigid wall, which is proven in this study overestimates the contact force, especially when large deformation of the tube and the ship bow occurs. It is also known that the collision with more flexible tubes can result in lower peak values of the contact force and longer impact duration. The numerical tests carried out in this study have shown these variations, despite small, to be more noticeable when different boundary conditions are assumed. The comparisons of the numerical simulation results with the current design curves from $\mathrm{DnV}$ on force and bow crushing distance are shown in Figure 29. It shows that, if the 'shared deformation' principle is assumed, the contact force must be related to the plastic deformations of the both bow and tube structure. Therefore, the value of the contact force that is reached until the bow starts to deform will be greater than that estimated by impacting with an idealized rigid cylinder. This value will also depend on the stiffness of the bow. The curves relating the strain energy to the bow deformation are shown in Figure 30. It should be noted that the suggested curves are based on the tube structures considered in the present study. They might not be extrapolated to other tubes in other offshore platform structures. 


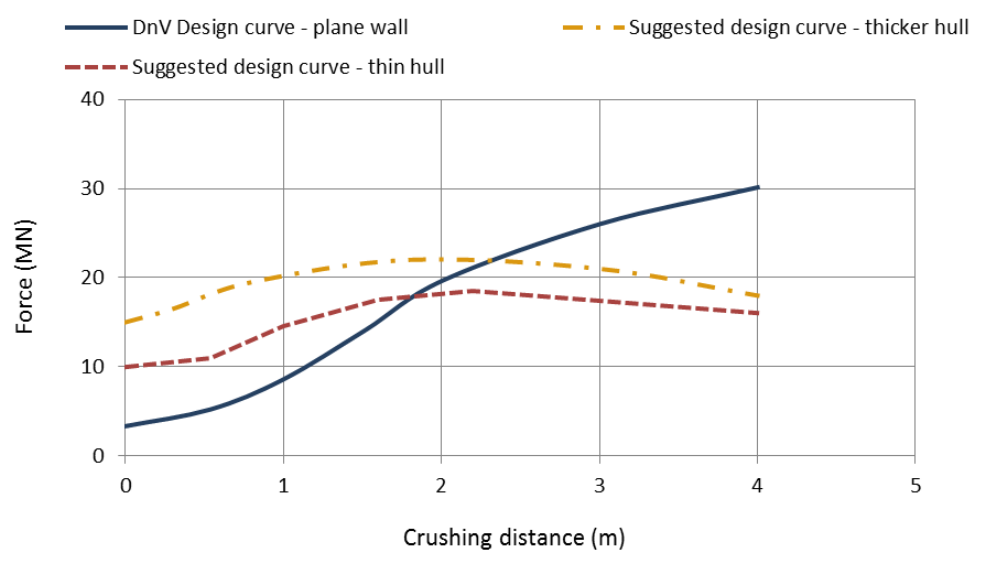

Figure 29. Force-deformation relationship for bulbous bow (ship displacement: 2000-5000 tons)

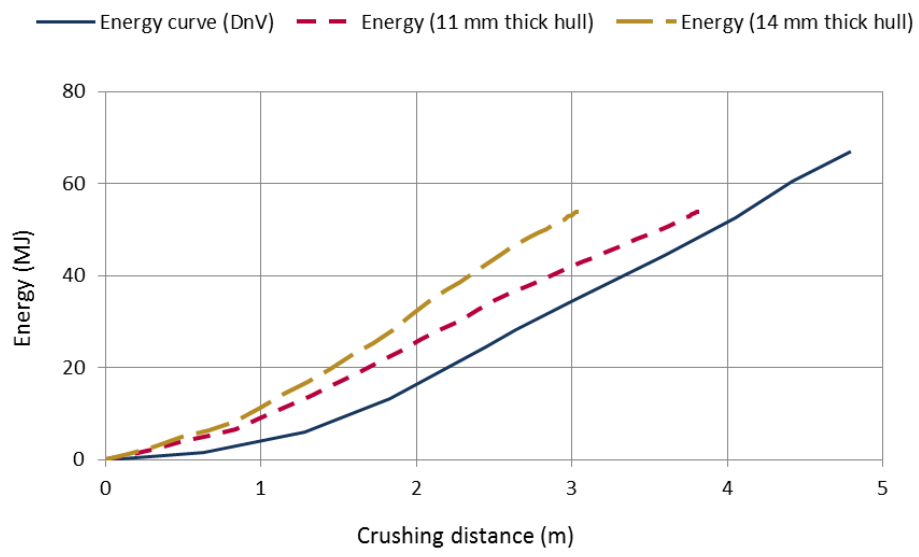

Figure 30. Energy-deformation relationship for bulbous bow (ship displacement: 2000-5000 tons)

Nevertheless, it is recommended that the response to impact when none of the structures behaves as ideally rigid be made in terms of strain energy dissipation. Obtaining the contact force from the deformations occurred simultaneously on both tube and bow structure is a very complex, whereas the energies can be easily related to the plastic deformations of the deformable bodies. The percentages of the initial kinetic energy to be dissipated through the different structures in contact depend on the relative stiffness of the two parts. Hence, for the impact scenario under consideration, particular care should be taken in order to correctly capture the deformation modes, rupture and plasticity that influence the stiffness variation during the plastic deformation and consequently the energy dissipation.

\subsection{Leg response}

For all the cases with different tubular structures and different wall thickness, diameter, length and boundary conditions considered in the present study, it is shown that the bow shape never remains unaffected after the impact. For the same reasons mentioned in section 6.1, the tube response is better predicted by means of strain energy. It is confirmed that the change of geometric parameters of the pipes, as well as boundary conditions or material properties can be treated through the normalization of the energy that is absorbed by the tube. The fact that a striker, a ship bow in this case, undergoes significant deformations does not seem significantly affect the expressions already in use for the 
assessment of energy dissipation. On the other hand, the normalization of the strain energy by the work done by an ultimate static load must take into account the nature of the load i.e., ship impacts are better characterized by distributed loads rather than a single point load and this will reflect on the deformation behavior/configuration of the tube. Since the DnV code takes into account the length of the dented (flattened) area, and the damage assessment can be done in terms of absorbed energy, its adequacy is therefore compared here. The DnV expression for the dissipated energy can be obtained from integrating the force-deformation relationship for denting, giving:

$$
\begin{gathered}
E=c_{1} \cdot\left(\frac{X^{c_{2}+1}}{c_{2}+1}\right) \cdot\left(\frac{1}{D}\right)^{c_{2}} \\
c_{1}=\left(\sigma_{y} \frac{t^{2}}{4} \sqrt{\frac{D}{t}}\right) \cdot\left(22+1.2 \frac{b}{D}\right) \cdot c_{3} \\
c_{2}=\frac{1.925}{3.5+\frac{b}{D}} \\
c_{3}=1.0, \quad \frac{N_{S d}}{N_{R d}} \leq 0.2
\end{gathered}
$$

where $b$ is the dent length along the tube longitudinal direction. A typical comparison for a particular tube is given in Figure 31. As shown the DnV equation gives very good predictions of energy absorption with respect to the local denting deformation.

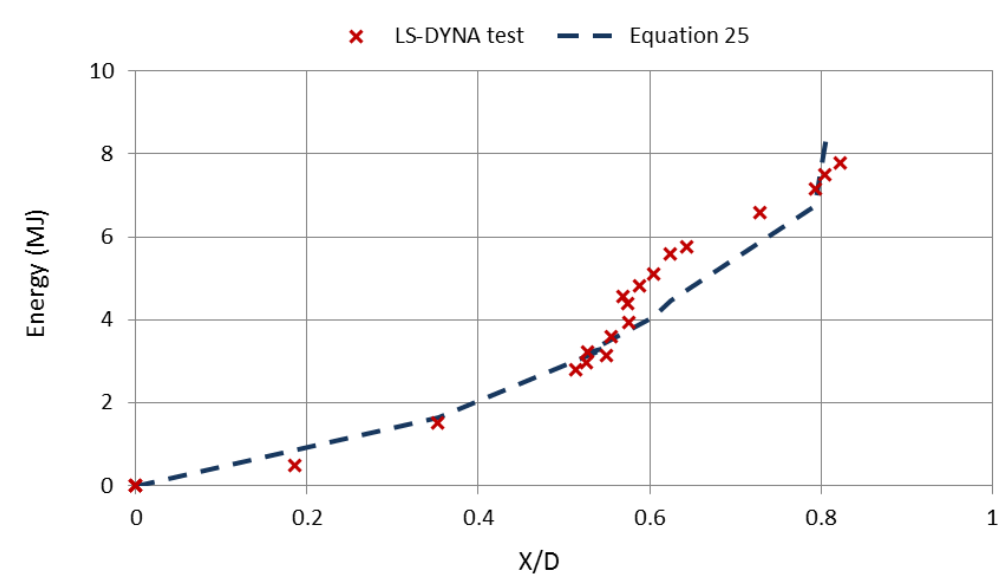

Figure 31. Energy-indentation estimation of steel tube $(\mathrm{L}=18 \mathrm{~m} ; \mathrm{t}=40 \mathrm{~mm} ; \mathrm{D}=2 \mathrm{~m})$

However, it should be noted that it is difficult to apply Equation 25 to predict the tube damage because the bow surface is not flat such that the contact area often cannot be properly defined. Moreover, the dented area can have not only different depths, but also discontinuities, especially at early stages of contact/bow deformation. For the studied case the estimation has been done by using an average depth derived from numerical simulation, which is usually not available in practice without performing numerical simulations.

In regards to the different deformation modes and their interaction, it has had already been verified that the absorbed energy increases nearly linearly with the increase of the maximum horizontal 
displacement of the tube membrane on the compressive side. This still holds true regardless of the boundary conditions.

Yet, in some cases involving very long tubes and high $L / D$ ratios, it is not clear of whether the large displacements measured could be related to the normalized absorbed energies in the same way the rest of the cases are treated. On the other hand, such members are less likely to be representative of typical jacket legs, which are usually shorter in length, and the ratio between the length of the leg and the ship depth is also small.

The numerical results also show that the obtained maximum contact force before rupture is therefore always larger than the ultimate load $P_{u}$ estimated based on the assumption of a concentrated point load and static analysis defined in Equation 12. This is because the actual case is not a point contact besides dynamic effect, which increases the material strength, as well as the the ship structure interaction. For instance, the clamped members with $P_{u}$ estimated as $12 \mathrm{MN}$ do not collapse after the contact force has reached to a peak of $16.3 \mathrm{MN}$. The same is obtained for a pinned member with $P_{u}$ estimated as $5.9 \mathrm{MN}$, but the peak contact force reached $16.3 \mathrm{MN}$, indicating again that the peak force from ship impact is different from the static capacity of the tube structure owing to dynamic effect as discussed above when considering the influence of preloading on peak impact force.

\section{Conclusion}

This paper presents numerical simulation results of ship impacts on offshore platform tubular structures. Compared to most previous studies of ship impacts on offshore structures that assumed mainly the low velocity broadside impacts during berthing and neglected ship-platform structure interaction by assuming either ship or platform structure as rigid, the present study considered ship and platform structure interaction. It is found that both ship bow structure and platform tube structure might experience large plastic deformation during impact. Neglecting their interaction and plastic deformation of either structure might lead to inaccurate predictions of impact loads, deformation, failure modes of the tube, and energy absorption. Intensive parametric simulations are carried out to study the influences of ship bow stiffness, tube dimension, thickness, boundary conditions, preload and impact velocity on ship-platform structure interaction. The numerical results are also compared with the design equations and analytical formulae suggested by other researchers in the literature for predicting impact loads, energy absorption and structure deformation. The adequacy of the current design practice is discussed. Based on the numerical simulation results, design curves are also suggested. These design curves derived with consideration of ship-platform structure interaction are believed giving more accurate predictions of impact loads, deformation and energy absorptions.

\section{Acknowledgement}

The authors would like to thank University of Western Australia (UWA) and Australian Research Council for providing scholarship and research funds to the first author to pursue his $\mathrm{PhD}$ study in UWA and carry out this research. 


\section{References}

Abramowicz W, Jones N. Dynamic axial crushing of square tubes. Int J Impact Eng 1984;2(2):179e208.

Amdahl J. Energy absorption in shipeplatform impacts. Dr. Ing. Thesis, Report No. UR-83-84. Throndeim: The Norwegian Institute of Technology; 1983.

Amdahl J, Johansen A. High-energy ship collision with jacket legs. In: Proceedings of the eleventh International offshore and polar engineering conference, Stavanger 2001. p. 373e7.

American Petroleum Institute. Recommended practise for planning, designing and constructing fixed offshore platforms e working stress design. RP 2A WSD. 21st ed.; 2000. Washington, DC., USA.

Aspden RJ, Campbell JD. The effect of loading rate on the elasto-plastic flexure of steel beams. Proc Roy Soc London Ser A (Math Phys Sci) 1966:266e85.

Cowper GR, Symonds PS. Technical Report No. 28 from Brown University to the Office of Naval Research under Contract Nonr-562(10), 1957.

Det Norske Veritas. Design against accidental loads. Recommended practise DNV-RP-C204; 2010.

Ellinas CP, Walker AC. Damage on offshore tubular bracing members. In: Proc IABSE colloquium on ship collision with bridges and offshore structures, vol. 42; 1985. p. 253e61. Copenhagen.

Furnes O, Amdahl J. Ship collisions with offshore plaftorms. Hamburg: Intermaritec' 80; 1980. p. 310 e28.

Jones N, Birch RS. Influence of internal pressure on the impact behaviour of steel pipelines. J Press Vess Tech 1996;118:464e71.

Jones N, Birch RS. Low-velocity impact of pressurised pipelines. Int J Impact Eng 2010;37:207e19.

Jones N, Birch SE, Birch RS, Zhu L, Brown M. An experimental study on the lateral impact of fully clamped mild steel pipes. Proc Inst Mech Eng Part E: J Process Mech Eng 1992:111e27.

Khedmati MR, Nazari M. A numerical investigation into strength and deformation characteristics of preloaded tubular members under lateral impact loads. J Mar Struct 2012;25:33e57.

Marsh KJ, Campbell JD. The effect of strain rate on the post-yield flow of mild steel. J Mech Phys Solids $1963 ; 11: 49$.

Minorsky VU. An analysis of ship collisions with reference to nuclear power plants. J Ship Res 1959;3(2):1e4.

Nielsen LP. Traffic and route data e safety of passanger RoRo vessels. Dept. of Ocean Engineering, Technical University of Denmark; 1995.

Oliveira JG. The behaviour of steel offshore structures under accidental collisions. Offshore Technology Conf., OTC 4136, Houston, USA; 1981. p. 187e98.

Paik JK. Practical techniques for finite element modelling to simulate structural crashworthiness in ship collisions and grounding (Part I: Theory). Ship Offshore Struct 2007;2(1):81e5. 
Paik JK. Practical techniques for finite element modelling to simulate structural crashworthiness in ship collisions and grounding (Part II: Verification). Ship Offshore Struct 2007;2(1):81e5.

Paik JK, Chung JY, Paik YM. On dynamic/impact tensile strength characteristics of thin high tensile steel materials for automobiles. Kor Soc Autom Eng 1999;7:268e78.

Paik JK, Thayamballi AK. Ultimate state limit design of steel plated structures. London: John Willey and Sons Ltd.; 2003.

Pedersen PT, Valsgard S, Olsen D. Ship impacts: bow collisions. Int J Impact Eng 1993; 13(2):163e87.

Sha Y, Hao H. Nonlinear finite element analysis of barge collision with a single bridge pier. Int J Eng Struct 2012;41:63e76.

Sha Y, Hao H. Numerical simulation of a continuous girder bridge to a barge impact and bridge damage detection. Int J Protect Struct 2013;4(1):79e96.

Sha Y, Hao H. Laboratory tests and numerical simulations of barge impact on circular reinforced concrete piers. Int J Eng Struct 2013;46:593e605.

Soreide TH, Kavlie D. Collision damages and residual strength of tubular members in steel offshore structure. In: Narayanna R, editor. Shell structures: stability and strength. New York: Elsevier Applied Science Publishers; 1985.p. $185 \mathrm{e} 220$.

The Overseas Coastal Area Development Institute of Japan. Technical standards and commentaries for port and harbour facilities in Japan. Japan: Daikousha Printing Co., Ltd; 2002.

Visser W. Ship collision and capacity of brace members of fixed steel offshore platforms. Houten: HSE Books; 2004. Research Report RR220.

Wierzzbicki T. Crushing behaviour of plate intersections, structural crashworthiness. chapter 3. London: Butterworth and Co. Publishers Ltd.; 1983. p. 66e95.

Yang PDC, Caldwell JB. Collision energy absorption of ships' bow structures. Int J Impact Eng 1988;7(2).

Zeinoddini M, Harding J, Parke GAR. Axially pre-loaded steel tubes under lateral loads. Int J Mech Sci 2006;48:1080e94. 